\title{
Neuromuscular systems in the fifth instar larva of silkworm Bombyx mori (Lepidoptera: Bombycidae): II- Abdominal musculature and its innervation
}

\author{
S. Sivaprasad* and P. Muralimohan ${ }^{1}$ \\ Department of Zoology, Smt. N. P. S. Government College for Women, Chittoor - 517002 ( A.P.), INDIA \\ ${ }^{1}$ Department of Sericulture, S.P. Women's University, Tirupati - 517502 (A.P. ), INDIA \\ *Corresponding author. E-mail: sivaprasadzoology@yahoo.co.in
}

\begin{abstract}
The gross organisation of abdominal musculature and its innervation by segmental ganglionic nerves were studied in the fifth instar larva of Bombyx mori. The musculature comprises dorsal, ventral and lateral groups of muscles, represented as external and internal layers. The dorsal group includes musculi dorsales interni mediales (DIM), musculi dorsales externi mediales (DEM), musculi dorsales interni laterals (DIL) and musculi dorsales externi laterales (DEL). The ventral group includes musculi ventrales interni mediales (VIM), musculi ventrales externi mediales (VEM), musculi ventrales interni laterales (VIL) and musculi ventrales externi laterales (VEL). The lateral group is represented by musculi laterales interni (LI) and musculi laterales externi (LE). The abdominal muscles are innervated by the dorsal (DN) and ventral (VN) nerves of abdominal ganglia. The DN innervates ventral internal, lateral internal and both dorsal external and internal muscles, while the VN innervates ventral external and lateral muscles. The sensory branches of DN and VN innervate the bodywall in the dorsal and ventral regions respectively with a sort of overlapping in the lateral region. The neuromuscular integration and intersegmental coordination in the abdominal region is discussed with reference to locomotion in the silkworm larva.
\end{abstract}

Keywords: Abdominal musculature, Bombyx mori, Ganglionic nerves, Innervation

\section{INTRODUCTION}

Ever since the studies of Snodgrass (1935, 1958), insect neuromuscular systems attracted the attention of several investigators. The morphological, physiological and anatomical studies over the years have contributed immensely to the existing knowledge on insect neuromuscular anatomy (Usherwood, 1967, 1968; Eaton, 1982; Yang, 1983; Bartos and Honegger, 1992; Brunn, 1998; Bullaro and Prete, 1999; Duve et al., 1999; Wolf and Harzsch, 2002; Kawasaki and Kita, 2004 ; Kent and Levine, 2004; Burrows, 2007; Copenhaver, 2007). Of late, extensive studies have been carried out on nerve topography and musculature of a variety of insects including the mosquito, Culiseta inormata (Owen, 2006), hymanopteran, Nomia melanderi (Youssef, 2005a, b), honey bee, Apis mellifera (Masuko, 2005; Shankland,2005), Drosophila and Calliphora (Sink, 2006; Spieb et al., 2007), cricket, Gryllus campestris and cockroach, Periplaneta amiricana (Honegger etal., 2004; Alsop, 2005; Davis, 2005; Klass, 2008), Further, the embryonic development of coxal muscles and their innervation in cockroach (Denburg and Fulop, 2005) and flight muscles in cricket (Ready and Josephson, 2005a,b) and the modulatory role of allatostatin on neuromuscular parameters (Kreiss et al., 1999) have also been reported. Although, insect musculature has been subjected to elaborate analysis and classification, the descriptions of the nervous system have been restricted to the examination of the peripheral distribution of abdominal and median nerves, the identification of motor and sensory neurons of the ganglia and tracing of the innervations of selected axons. Further, the available studies on neuromuscular systems of silkworm and other lepidopteran insects (Libby, 1959; Randall, 1968; Kondoh and Obara, 1982; Sivaprasad and Muralimohan, 1999), have not adequately focussed on detailed organisation of the segmental musculature and nerve-muscle integration in different segments of the insect body. Hopefully, such studies on Bombyx mori will have double advantage. Firstly, they help in analyzing the basic tenets of nerve-muscle integration in insects and its important role in body movements, locomotion, thermoregulation, respiration and the circulation of body fluids. Secondly, from economic point of view, it helps ascertain the mechanism underlying the cocoon spinning behaviour by this insect, which indirectly contributes to the sericultural industry in the form of quality silk. The present study examines the gross organisation of the abdominal musculature, and its innervation patterns in the fifth instar larva of Bombyx mori. Though, the study is not exhaustive, nevertheless provides insights for future investigations in this direction. 


\section{MATERIALS AND METHODS}

The fifth instar larva of multivoltine $\mathrm{NB}_{4} \mathrm{D}_{2}$ strains of Bombyx mori, reared in the laboratory as per Krishnaswami (1986), were fixed for $24 \mathrm{~h}$ in a fixative consisting of $25 \mathrm{ml}$ of $40 \%$ formalin, $1.25 \mathrm{ml}$ of acetic acid and $10 \mathrm{~g}$ of chloral hydrate in $100 \mathrm{ml}$ of distilled water (Chauthani and Callahan, 1966). They were pinned dorsal side up on a wax block and dissected out in the middorsal region from the last abdominal segment to the head. The gut was carefully removed along with the fatbody and attached tracheae.

The gross organization of the abdominal musculature and the branching and innervation pattern of the nerves of the eight abdominal ganglia ( $\mathrm{AG}_{1}$ to $\mathrm{AG}_{8}$ ) and the nerve-muscle anatomy of eight abdominal segments $\left(\mathrm{AS}_{1}\right.$ to $\mathrm{AS}_{8}$ ) starting with $\mathrm{AS}_{1}$ through $\mathrm{AS}_{8}$ were studied under Labomed Stereo-Binocular Microscope, by applying $1 \%$ methylene blue stain in distilled water. Occasionally alcoholic Bouin's fluid was added to the preparation to stain the nerve-muscle preparation blue-green. In such preparations the ramifications of the nerves and their finer branches could be distinguished well, counted and their innervation traced. Sketches of abdominal segmental musculature and its innervation pattern as seen in the right half of all abdominal segments were made directly from the dissections. At least five to ten larvae were used to draw the sketches from each hemi-segment.

\section{RESULTS}

The present report on silkworm neuromuscular systems, presented in Figs. 1 to 17 and in Tables 1 and 2, encompasses the abdominal musculature and its innervation by the segmental ganglionic nerves.

I. Abdominal musculature : In the silkworm larva the abdominal muscles are organized in the form of elongated bands that represent a stereotyped pattern of segmental arrangement. The muscles that occur in each segment as separate bands throughout their length were considered as individual muscles and were counted accordingly, while those fused partly or wholly were considered as branches of the same muscle. The muscles are designated based on the nomenclature used by Snodgrass (1935). In all, 12 types of muscles, arranged in two distinct layers viz., external and internal are represented in the abdomen. Depending on their site of location in the segment, the muscles are broadly categorized into three principal groups, viz., dorsal, ventral and lateral ones.

\section{(A) Dorsal abdominal muscles}

1)The musculi dorsales interni mediales (DIM): The longitudinal intersegmental muscle bands present in the mid dorsal region of the segments are designated as the musculi dorsales interni mediales (DIM) or dorsal internal median muscles. They are of segmental length and are attached to the intersegmental folds in all the pregenital abdominal segments. Their number in each segment ranges from 8 to 16 (Figs. 1,3,5,7,9,11,13, 15; Table 2), except for the last one, wherein only two muscle bands are represented Fig. 15).

2)The musculi dorsales interni laterales (DIL): These are the longitudinal and oblique intersegmental muscles present in the dorsolateral regions of the segment. They are of segmental length and are arranged in the inner tergal area in all the abdominal segments and are attached to intersegmental folds at both the ends. Their number ranges from 4 to 8 in different abdominal segments (Figs. 1,3,5,7, 9,11,13, 15 and Table 2).

3)The musculi dorsales externi mediales (DEM): The short dorsal longitudinal external muscles lying in the posterior mesal part of the abdominal terga and occupying the exterior and peripheral position of the abdominal segment are designated as the musculi dorsales externi laterales (DEL) or dorsal external median muscles. They are slightly oblique in disposition with an anteriorly outward slant and with sites of attachment at the intersegmental walls. The number of DEM correspond to that of DIM and ranges from 8 to 16 in all segments except the last one where only two muscles are represented (Figs. 1,3,5,7, 9,11,13, 15 and Table 2).

4)The musculi dorsales externi laterales (DEL): These are the short dorsal longitudinal muscles occupying the exterior and peripheral portion in the posterolateral part of all pregenital abdominal segments. Also called dorsal external lateral muscles, they exhibit a slight oblique disposition with an anteriorly outward slant, and are attached to the intersegmental walls at both the ends (Figs. 1,3,5,7, 9,11,13, 15 and Table 2).

\section{B) Ventral abdominal muscles}

\section{5)The musculi ventrales interni mediales (VIM): The} longitudinal intersegmental muscle strips present in the mid-ventral region of the segment are called musculi ventrales interni mediales (VIM) or ventral internal median muscles. They are of segmental length, lying in the inner segmental area in all the pregenital abdominal segments, with their attachment sites at intersegmental walls. Their number ranges from 4 to 16 in different abdominal segments (Figs. 1, 3, 5, 7, 9, 11, 13, 15 and Table 2).

6) The musculi ventrales interni laterales (VIL): These are longitudinal intersegmental muscle strips present in the ventrolateral areas of the segment. Also called ventral internal lateral muscles, the VIL are attached to the intersegmental walls at both the ends and are located in the inner sternal area in all the pregenital abdominal segments. Their number in abdominal segments ranges from 7 to 20 (Figs. 1,3,5,7,9,11,13,15 and Table 2).

7)The musculi ventrales externi mediales (VEM): The short ventral longitudinal muscles lying in the posterior mesal part of the abdominal sterna in the exterior peripheral position of all abdominal segments are called musculi 


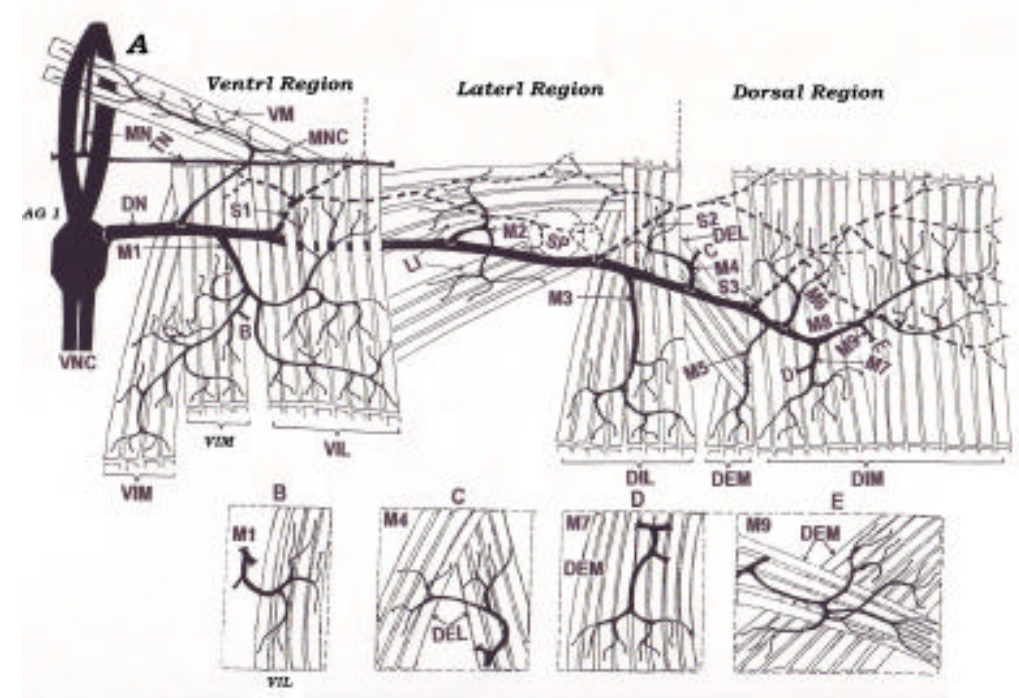

Fig. 1. (A). Musculature of the first abdominal hemi-segment and its innervation by the dorsal nerve (DN) of the first abdominal ganglion ( $A G_{1}$ ), in the fifth instar larva of Bombyx mori. Insets $\boldsymbol{B}, \boldsymbol{C}, \boldsymbol{D}, \boldsymbol{E}$ : The distribution of motor branches $M_{1}, M_{4}$ and $M_{7}$ and $M$ respectively. DN. dorsal nerve; DEL. musculi dorsales externi laterales; DEM. musculi dorsales externi mediales; DIL. musculi dorsales interni laterales; DIM. musculi dorsales interni mediales; LI. musculi interni laterales; $M_{1-} M_{9}$. first to $9^{\text {th }}$ motor nerves; MN. median nerve; MNC. median nerve connective; $S_{1}$ to $S_{3}$. sensory nerves 1 to 3; SP. spiracle; TN. transverse nerve; VIL. musculi ventrales interni laterals; VIM. musculi ventrales interni mediales; VNC. ventral nerve chord; Note: The motor branches $\left(M_{1-} M_{9}\right)$ are shown in bold thick lines and the sensory branches $\left(S_{1}\right.$ to $\left.S_{3}\right)$ in broken lines.

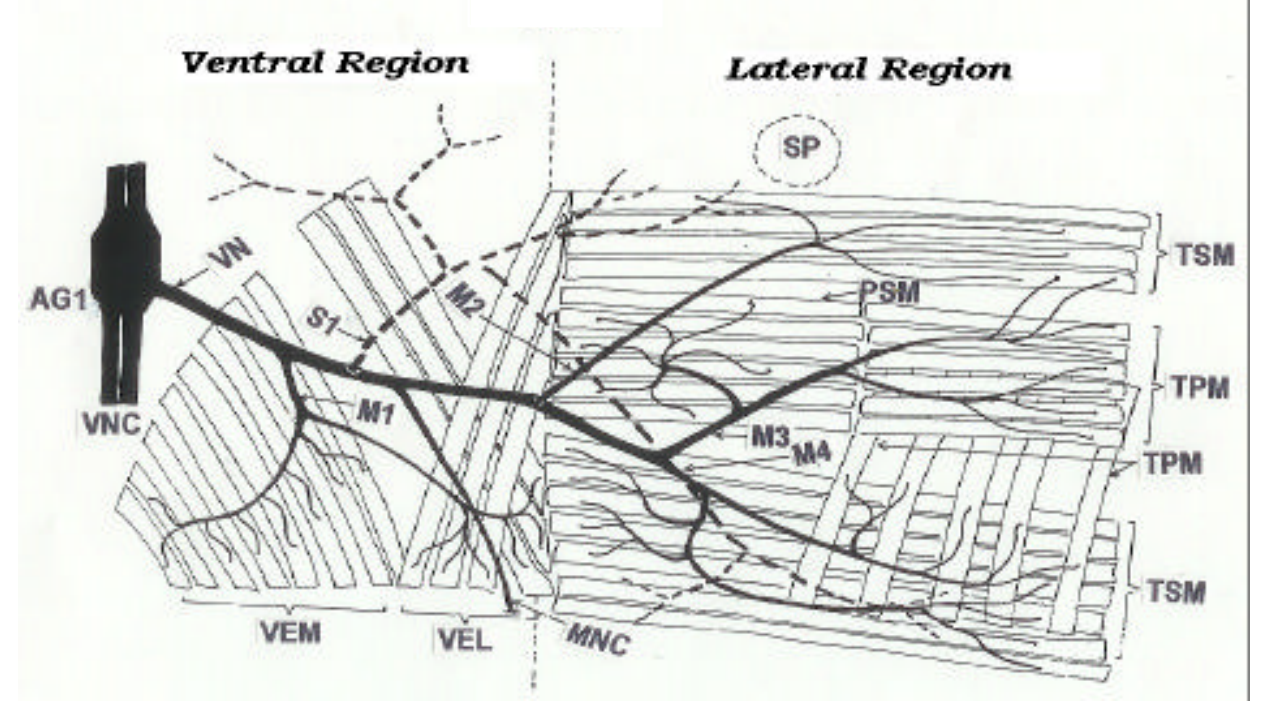

Fig. 2. Musculature of the first abdominal hemi-segment and its innervation by the ventral nerve (VN) of the first abdominal ganglion $\left(A G_{1}\right)$, in the fifth instar larva of Bombyx mori. PSM . pleurosternal muscles; TSM. tergosternal muscles; TPM. tergopleural muscles; VEL.musculi ventrales externi laterales; VEM. musculi ventrales externi mediales; Remaining notations are the same as in the legend for Fig. 1.

ventrales externi mediales (VEM) or ventral external median muscles. They arise on the posteromesal part of the sternum and are obliquely disposed with an anterior outward slant and are attached to intersegmental wall at one end and to the median ventrum at the other end. Their number is not constant, but shows great variation ranging from 3 and 17 in each segment of abdomen (Figs. 2, 4, 6, 8, 10, 12, 14 and Table 2).
8)The musculi ventrales externi laterales (VEL): The short ventral longitudinal muscle bundles occupying the exterior and peripheral position in the posterolateral part of the abdominal sterna are known as the musculi ventrales externi laterales (VEL) or ventral external lateral muscles. They are obliquely disposed with an anterior inward slant in all the pregenital abdominal segments. They arise on the posterolateral portions of the sterna 
and are inserted on the ventrum in the ventrolateral region of the hemi-segment. Their number ranges from 3 to 10 in different abdominal segments (Figs. 2, 4,6,8,10,12, 14 and Table 2).

\section{C). Lateral abdominal muscles}

9)The musculi laterales interni (LI): The horizontal or oblique muscle strips located in the inner lateral portions of all pregenital abdominal segments are identified as the musculi laterales interni or lateral internal muscles. The act as spiracular muscles (SM) and appear in the form of horizontal or oblique intrasegmental muscles lying in the inner lateral region near the spiracles in all abdominal segments, with their attachment sites on the dorsum below the dorsal muscles at one end and on the ventrum below the ventral muscles at the other end. They are arranged in two groups of 4 each in all abdominal segments (Figs. 1,3,5,9,11,13 and 15) except the $7^{\mathrm{h}}$ abdominal segment (Fig. 7) in which 12 muscles are organized into two groups $(8+4)$ near the spiracle.

10) The musculi laterales externi (LE): The horizontal and oblique groups of intrasegmental muscle bundles occupying the lateral exterior and peripheral portions of all pregenital abdominal segments are denoted as the lateral external muscles or musculi laterales externi (LE). These include tergopleural (TPM), tergosternal (TSM), pleurosternal (PSM), tergocoxal (TCM) and pleurocoxal (PCM) muscles. The TPM are attached to the tergum and pleural plates and occur in two or three horizontal and / or oblique groups in all abdominal segments except the eighth one, in which they are conspicuous by their absence. Their number ranges from 11 to 22 in each segment. TSM are represented in the form of horizontal groups in $1^{\text {st }}, 2^{\text {nd }}, 5^{\text {th }}, 6^{\text {th }}$ and $7^{\text {th }}$ abdominal segments, and their number ranges from 4 to 11 with their attachments at the tergum and pleuron (Figs. 2,4,6,8, 10,12,14). The PSM are present in 6 to 12 numbers in four abdominal segments $\left(1^{\text {st }}, 2^{\text {nd }}, 3^{\text {rd }}, 5^{\text {th }}\right)$, in the form of horizontal bands connecting the pleuron with the sternum (Figs. 2, 4, 6, $10)$. The TCM are present only in the $4^{\mathrm{h}}$ abdominal segment in the form of a horizontal group comprising 8 muscle strips connecting the tergum with the pleuron. The PCM also occurs in the $4^{\text {th }}$ abdominal segment in the form a horizontal group of 3 muscles that connects the pleuron with the coxal base of the pro-leg (Fig. 8).

11)Sternocoxal muscles (SCM) : These are the horizontal or oblique peripheral intra segmental muscle bundles lying in the sternal region of the proleg-bearing third, fourth, fifth and sixth abdominal segments (Figs. 6,8,10,12). They arise from the sternal wall and are attached to the coxal base at its rim or inserted on the coxal wall within the cone-shaped coxa. The SCM are essentially similar in arrangement in all prolegs and their number varies from 15 to 30 within the coxa. Additional groups, each consisting of 11 and 2 SCM occur outside the coxa in the third and fourth abdominal segments respectively (Figs.
6 and 8), where as they are absent in the fifth and sixth abdominal segments (Figs. 10, 12).

12)Cercal muscles (CM): These are oblique intrasegmental muscles lying in the cercal region of the eighth abdominal segment. They arise on the sternal wall and are attached to the postpedes (anal prolegs) at the rim. There are about 19 such muscles arranged in 3 groups in each postped of the segment (Fig. 6).

II. Innervation patterns :The abdominal musculature of silkworm is innervated by the segmental ganglionic nerves emerging from the eight abdominal ganglia $\left(\mathrm{AG}_{1}\right.$ to $\mathrm{AG}_{8}$ ). In silkworm, they include a pair of lateral nerves, designated the dorsal (DN) and ventral (VN) nerves. The former originates on the dorsal aspect and the latter on the ventral aspect of the ganglion. Their branching and innervation patterns were traced and presented in Figs. 1 to 17 and in Tables 1 and 2. In their course, the ganglionic nerves give out two types of branches, the motor branches $\left(\mathrm{M}_{1}, \mathrm{M}_{2}, \mathrm{M}_{3}\right.$, etc) to the muscles and sensory branches $\left(\mathrm{S}_{1}, \mathrm{~S}_{2}, \mathrm{~S}_{3}\right.$ etc) to the body wall. Thenerve branch connected to the muscle was considered as the motor branch while that innervates the body wall as the sensory branch. In each hemisegment, they follow a specific course from the point of their origin to the point of destination. Soon after its origin from the ganglion, the DN enters the midventral region and then passes into the lateral region, where it runs past the spiracle and finally reaches the dorsal region in all segments. On the other hand the $\mathrm{VN}$ is extended into the ventral and lateral regions of the segment, but does not reach the dorsal region. In its course, the DN passes over the inner face of the musculi ventrales interni mediales (VIM) and below the musculi ventrales interni laterals (VIL) in the ventral region, and on the inner face of the musculi dorsales interni laterals (DIL) and in between the musculi dorsales interni mediales (DIM) and musculi dorsales externi mediales (DEM) in the dorsal region. The VN runs peripherally in between the external and internal layers of ventral muscles (VIM and VEM) in all abdominal segments. Their orientation in the abdominal hemi-segment may be anteroventral (AV), posteroventral $(\mathrm{PV})$, anterolateral $(\mathrm{AL})$, posterolateral (PL), anterodorsal (AD), posterodorsal (PD) or dorsolateral (DL).

A) Motor branches of dorsal and ventral nerves : The number of motor branches emanating from the DN ranges from 5 to 9 , and that coming from the VN varies from 3 to 6 in each segment.

i.The DN of first abdominal ganglion $\left(\mathrm{AG}_{1}\right)$ sends 9 motor branches $\left(M_{1}\right.$ to $\left.M_{9}\right)$, which innervate about 79 muscle strips of the first abdominal hemi-segment, including 8 VIM in the ventral region, 12 VIL in the ventrolateral region, $8 \mathrm{LI}$ in the lateral region, $8 \mathrm{DIL}$ and 8 DEL in the dorsolateral region, 20 DEM and 15 DIM in the dorsal region. It also innervates two ventral muscles 


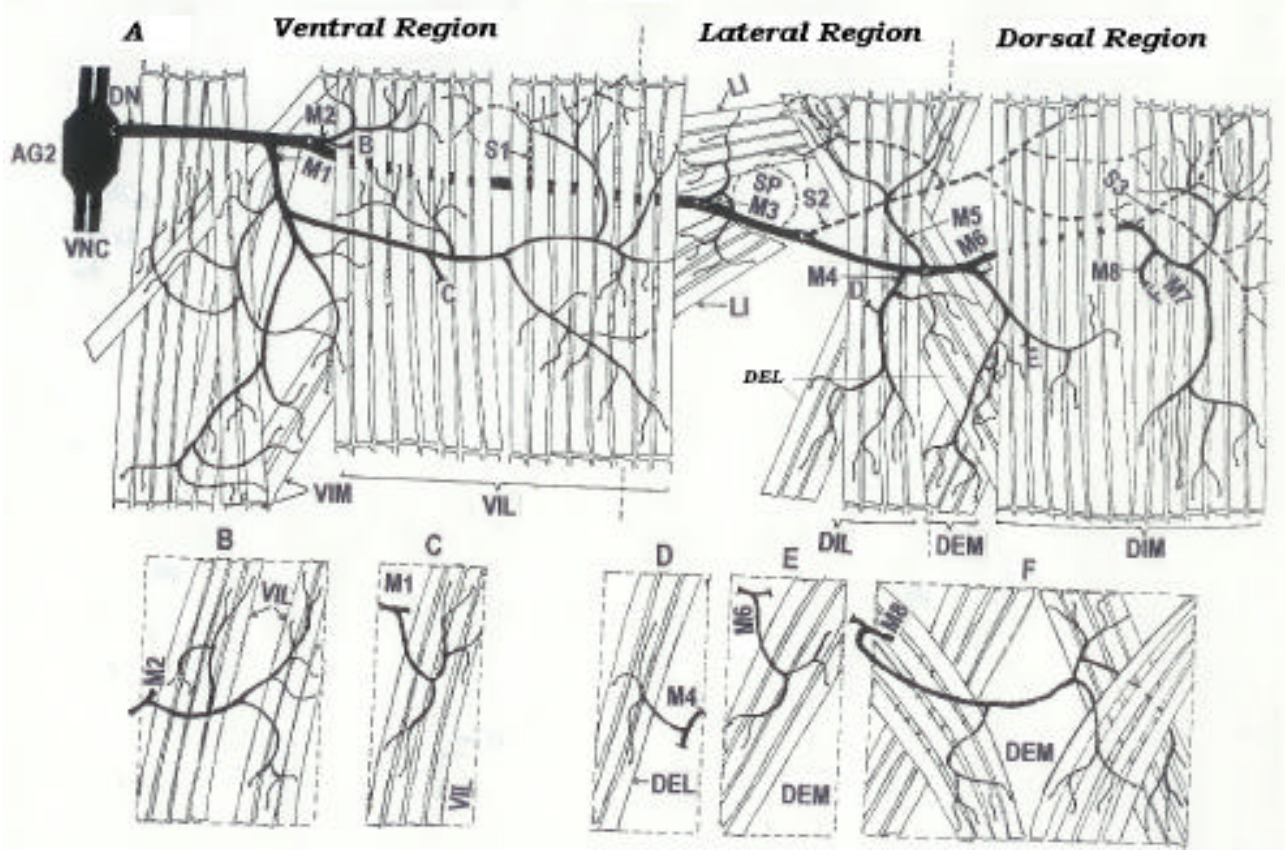

Fig. 3 (A). Musculature of the second abdominal hemi-segment and its innervation by the dorsal nerve (DN) of the second abdominal ganglion $\left(A G_{2}\right)$, in the fifth instar larva of Bombyx mori. Insets $\boldsymbol{B}, \boldsymbol{C}, \boldsymbol{D}, \boldsymbol{E}, \boldsymbol{F}$ : The distribution of motor branches $M_{2}$, $M_{1}, M_{4}, M_{6}$ and $M_{8}$ respectively. Remaining notations are the same as in the legend for Fig. 1.

(VM) in the prothorax (Fig.1 and Table 2). The VN gives out 4 motor branches in the ventral and ventrolateral regions of the hemi-segment which innervates 42 muscle bundles, comprising 8 VEM, 6 VEL, 11 TSM, 6 PSM and 11 TPM (Fig. 2 and Table 2).

ii. The $\mathrm{DN}$ of second abdominal ganglion $\left(\mathrm{AG}_{2}\right)$ gives 8 motor branches $\left(M_{1}\right.$ to $\left.M_{8}\right)$ in all the regions of the second abdominal hemi-segment, which innervate about 83 muscle strips including 11 VIM, 20 VIL 8 LI, 7 DIL 7 DEL, 14 DIM and 16 DEM. (Fig. 3 and Table 2). The VN gives out 6 motor branches in the ventral and ventrolateral regions of the hemi-segment which innervates about 55 muscle bundles, comprising 17 VEM, 10 VEL, 4 TSM, 16 TPM, 8 PSM (Fig.4 and Table 2). Additionally, a branch of $\mathrm{M}_{6}$ enters the next (third) abdominal segment in the lateral region, where it innervates $8 \mathrm{LE}$.

iii.The $\mathrm{DN}$ of third abdominal ganglion $\left(\mathrm{AG}_{3}\right.$ ) gives 6 motor branches $\left(\mathrm{M}_{1}\right.$ to $\left.\mathrm{M}_{6}\right)$ in the third abdominal hemisegment, which innervate about 79 muscle strips including 16 VIM, 17 VIL, 8 LI, 7 DIL, 7 DEL, 16 DIM and 8 DEM. (Fig.5 and Table 2). The VN gives out 4 motor branches in the ventral and ventrolateral regions of the hemisegment which innervates about 69 muscle bundles, comprising 8 VEM, 4 VEL, 30 SCM, 5 SPM and 22 TPM (Fig. 6 and Table 2).

iv. The $\mathrm{DN}$ of fourth abdominal ganglion $\left(\mathrm{AG}_{4}\right)$ gives 8 motor branches $\left(\mathrm{M}_{1}\right.$ to $\left.\mathrm{M}_{8}\right)$ in the fourth abdominal hemisegment, which innervate about 75 muscle strips including
13 VIM, 12 VIL 12 LI, 7 D IL, 4 DEL, 16 DIM and 11 DEM. (Fig.7 and Table, 2). The VN gives out 4 motor branches in the ventral and ventrolateral regions of the hemisegment which innervates about 58 muscle bundles, comprising 3 VEM, 3 VEL, 26 SCM, 8 TCM, 3 PCM, 15 TPM in the fourth abdominal segment, and $8 \mathrm{LE}$ the fifth abdominal segment (Fig. 8 and Table 2).

v. The $\mathrm{DN}$ of fifth abdominal ganglion ( $\mathrm{AG}_{5}$ ) gives 8 motor branches $\left(M_{1}\right.$ to $\left.M_{8}\right)$ in the sixth abdominal hemisegment, which innervate about 86 muscle strips including 14 VIM, 19 VIL, 8 LI, 8 DIL, 5 DEL 16 DIM and 16 DEM. (Fig.9; Table 2). The VN gives out 6 motor branches in the ventral and ventrolateral regions of the fifth abdominal hemi-segment which innervates about 55 muscle bundles, comprising 7 VEM, 3 VEL, 17 SCM, 6 PSM, 4 TSM and 18 TPM. A branch from $\mathrm{M}_{6}$ of VN crosses over to the next abdominal (sixth) segment and innervates $8 \mathrm{LE}$, additionally (Fig. 10 and Table 2).

vi. The $\mathrm{DN}$ of sixth abdominal ganglion ( $\mathrm{AG}_{6}$ ) gives 6 motor branches $\left(\mathrm{M}_{1}\right.$ to $\left.\mathrm{M}_{6}\right)$ in the sixth abdominal hemisegment, which innervate about 67 muscle strips including 10 VIM, 10 VIL, 8 LI, 6 DIL, 3 DEL, 14 DIM and 16 DEM. (Fig. 11 and Table 2). The $\mathrm{VN}$ gives out 4 moor branches in the ventral and ventrolateral regions of the hemisegment which innervates about 52 muscle bundles, comprising 7 VEM, 4 VEL, 18 SCM, 5 TSM, 4 PSM, 14 TPM in the sixth abdominal segment (Fig. 12; Table 2). In addition the $\mathrm{M}_{1}$ of $\mathrm{VN}$ gives a small branch designated 


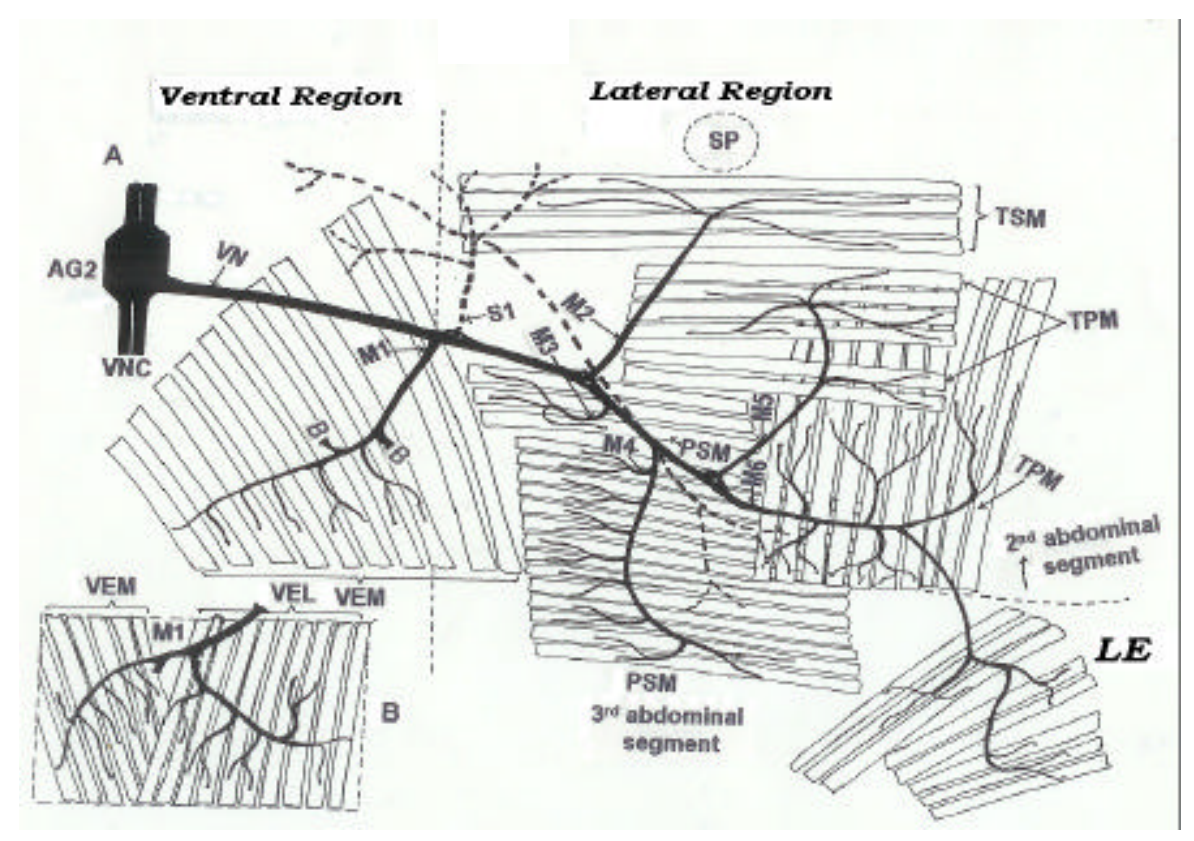

Fig. 4. Musculature of the second abdominal hemi-segment and its innervation by the ventral nerve (VN) of the second abdominal ganglion $\left(\mathrm{AG}_{2}\right)$, in the fifth instar larva of Bombyx mori. LE: musculi externi laterales; PSM . pleurosternal muscles;Remaining notations are the same as in the legends for Figs. 1 and 2.

median nerve connective (MNC) that connects the median nerve in the next segment (Fig. 12).

vii. The $\mathrm{DN}$ of seventh abdominal ganglion $\left(\mathrm{AG}_{7}\right)$ gives 6 motor branches $\left(\mathrm{M}_{1}\right.$ to $\left.\mathrm{M}_{6}\right)$ in the seventh abdominal hemi-segment, which innervate about 49 muscle strips including 4 VIM, 12 VIL, 8 LI, 6 DIL, 3 DEL, 8 DIM and 8 DEM. (Fig. 13 and Table 2). The VN gives out 3 motor branches $\left(\mathrm{M}_{1}\right.$ to $\left.\mathrm{M}_{3}\right)$ in the ventral and ventrolateral regions of the hemi-segment which innervates about 34 muscle bundles, comprising 8 VEM, 4 VEL, 11 PSM and 11 TPM in the seventh abdominal segment (Fig. 14 and Table, 2).

viii. Since, the eighth abdominal ganglion is confluent with the seventh abdominal ganglion and it is located in the seventh abdominal segment, the DN of eighth abdominal ganglion $\left(\mathrm{AG}_{8}\right)$ is a longer one and extends into the eighth abdominal segment where it gives 5 motor branches $\left(\mathrm{M}_{1}\right.$ to $\left.\mathrm{M}_{5}\right)$ for about 29 muscle strips including 4 VIM, 7 VIL 8 LI, 4 DIL, 2 DEL, 2 DIM and 2 DEM (Fig. 15 and Table 2). The $\mathrm{VN}$ follows similar course as $\mathrm{DN}$ and gives out 4 motor branches $\left(M_{1}\right.$ to $\left.M_{4}\right)$ in the ventral and ventrolateral regions of the eighth abdominal segment, which innervates about 24 muscle bundles, comprising 6 pyloric muscles (PM) and 18 cercal muscles $(\mathrm{CM})$ (Fig. 16 and Table 2).

\section{B) Sensory branches of dorsal and ventral nerves}

i. The sensory branches of both DN and VN of all the abdominal ganglia are shown in the form of dotted lines in fig. 1 to 16. They always arise on the dorsal aspect of the nerves and their number varies from 1 to $3\left(S_{1}\right.$ to $\left.S_{3}\right)$. If their number is 3 as in the case of $D N$ of $A_{1}, A G_{2}$ and $A_{8}$, the $S_{1}$ arises in the ventrolateral region and the $S_{2}$ and $\mathrm{S}_{3}$ arise in the dorsolateral and dorsal regions respectively (Figs. 1,3, 15 and Table 2). Conversely, if there are two branches as in the case of $\mathrm{DN}$ of $\mathrm{AG}_{2}, \mathrm{AG}$ ${ }_{4}, \mathrm{AG}_{5}, \mathrm{AG}_{6}$ and $\mathrm{AG}_{7}$, the $\mathrm{S}_{1}$ and $\mathrm{S}_{2}$ arise separately in dorsolateral and middorsal regions of the segment (Figs. 5, 7,9,11,13 and Table 2).

ii. The VN of all abdominal ganglia gives off only one sensory branch (S1) in the ventral region of the segment. It innervates the body wall in the ventral and ventrolateral regions of the respective abdominal segments (Figs. 4,6,8,10,12,14, 16 and Table 2).

iii. Projections of cercal nerve $(\mathbf{C N})$ : The peculiarity of the last abdominal ganglion $\left(\mathrm{AG}_{8}\right)$ is that it possesses a cercal nerve in addition to the paired DN and VN. It arises in between these two nerves and runs down posteriorly into the conical anal papilla that bears the cerci laterally and anus at its apex. The $\mathrm{CN}$ splits into three prominent branches and innervates the body wall in the midventral cercal and lateral regions of the last segment besides the anal papillae. Since, the $\mathrm{CN}$ is a sensory nerve; it bears no motor branches (Fig.17).

\section{DISCUSSION}

The insect muscle is implicated in a multitude of functions such as respiration, thermiogenesis, circulation of body fluids, body movements and locomotion (Kawasaki and Kita, 2004 and Sink, 2006). The muscle in silkworm has an additional function of cocoon spinning which indirectly influences the sericulture industry in terms of silk production and productivity.

I. Abdominal musculature : The fundamental pattern of 


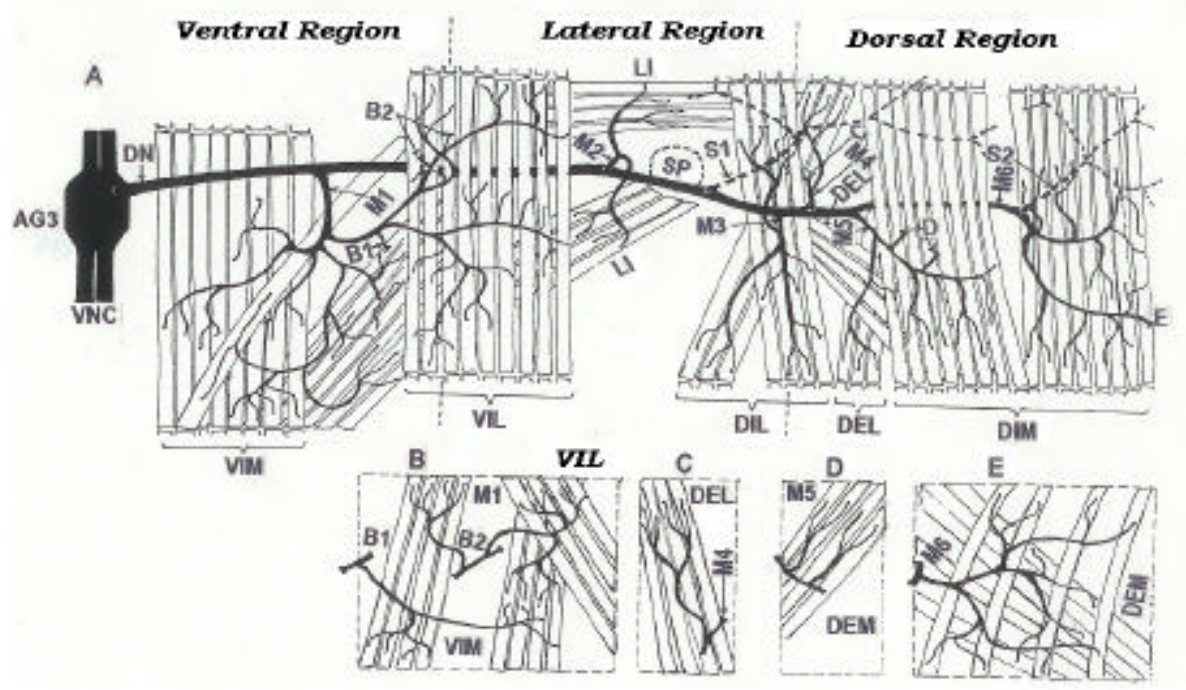

Fig. 5. (A). Musculature of the third abdominal hemi-segment and its innervation by the dorsal nerve (DN) of the third abdominal ganglion $\left(A G_{3}\right)$, in the fifth instar larva of Bombyx mori. Insets $\boldsymbol{B}, \boldsymbol{C}, \boldsymbol{D}, \boldsymbol{E}$ : The distribution of motor branches $M_{1}, M_{4}$ and $M_{5}$ and $M_{6}$ respectively. Remaining notations are the same as in the legend for Fig. 1.

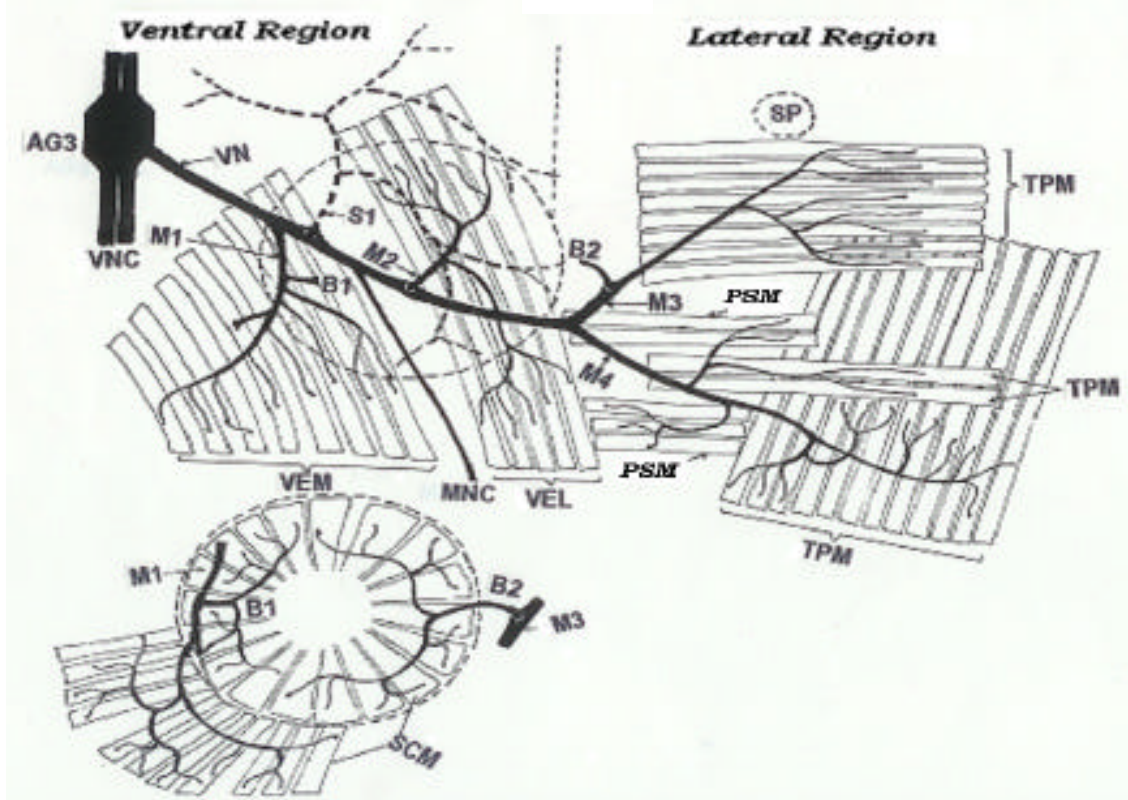

Fig. 6. Musculature of the third abdominal hemi-segment and its innervation by the ventral nerve (VN) of the third abdominal ganglion $\left(\mathrm{AG}_{3}\right)$, in the fifth instar larva of Bombyx mori. Inset: Arrangement of sternocoxal muscles (SCM) in the coxal region of the abdominal proleg and its innervation by $M_{1}$ and $M_{3}$. SPM. sternopleural muscles; Remaining notations are the same as in the legends for Figs. 1 and 2.

abdominal musculature and nerve topography in the silkworm larva is in consonance with the segmentation of the body, with a stereotyped pattern of arrangement as described in various other insects (Snodgrass, 1935, 1958; Deshpande and Pathan, 1982; Shankland, 2005; Youssef, 2005a,b and Sink, 2006). However, minor variations are detectable in the number and disposition of muscles in different segments of the abdomen.
The potential number of abdominal muscles displays variation segment-wise, region-wise and layer-wise (i.e. external and internal) within each abdominal hemisegment (Table 1). The total number of muscles is 113 in the $\mathrm{AS}_{1}, 138$ in $\mathrm{AS}_{2}, 148$ in $\mathrm{AS}_{3}, 133$ in $\mathrm{AS}_{4}, 141$ in $\mathrm{AS}_{5}, 119$ in $\mathrm{AS}_{6}, 83$ in $\mathrm{AS}_{7}$ and 53 in $\mathrm{AS}_{8}$. Comparatively, less number of muscles are present both at anterior and posterior ends of the larval body. The number of muscles 
distributed in different sectors of the larva appears to vary as a function of the size of its body, with more muscles occurring in the broader middle region of the abdomen and fewer muscles in the narrow tapering posterior segments. In all, each half of the abdomen possesses about 928 muscles in all abdominal segments and in both extrinsic and intrinsic layers. Considering the bilateral symmetrical nature of the larval body, about 1856 of muscles are present in the abdomen of silkworm when both left and right halves of the larval are taken into consideration (Table 1).

The number of muscles in each region of the abdominal hemi-segment is also not constant. It varied from 10 to 45 in the dorsal region, 31 to 58 in the ventral region and 8 to 38 in the lateral region. In the entire abdomen, there are about 305 muscles in ventral region, 250 in lateral region and 282 in the dorsal region. The layer-wise projections indicate that the external layer comprises more muscles (426) than the internal layer (411), indicating the more complex nature of the extrinsic musculature compared to its intrinsic counterpart.

The dorsal group of muscles comprises primarily the longitudinal bundles of segmental length attached to the intersegmental folds. The internal dorsals retain their longitudinal position and segmental length and include two separate groups of muscle bundles called musculi dorsales interni mediales (DIM) and musculi dorsales interni laterales (DIL). The external dorsals, on the other hand, are seldom of segmental length but occur typically as short oblique or transverse groups of muscle bundles lying predominantly in the posterior part of segments.
They include musculi dorsales externi mediales (DEM) and musculi dorsales externi laterales (DEL). The number of dorsal muscles in silkworm ranges from 10 to 45 in different segments of the abdomen (Table 1). Functionally, these muscles act as tergal protractors since their contraction lengthens the body by decreasing the overlap of segments (Snodgrass, 1935).

The ventral group muscles of the abdomen displays similar disposition like that of dorsal group, and includes both external and internal layers of muscle bundles. This internal group includes musculi ventrales interni mediales (VIM) and musculi ventrales interni laterals (VIL), which are typically intersegmental and are known to act as retractors of ventral segments. The external group includes musculi ventrales externi mediales (VEM) and musculi ventrales externi laterales (VEL) and represented in the form of short and oblique strips in the posterior half of the segments. The total number of ventral muscles in the abdomen of silkworm is also not constant, but ranges from 31 to 58 in different segments. Both VEM and VEL act as sternal protractors as their contraction causes reversal in position of body segments. The locomotion in all insects (Barth, 1937) and probably in the silkworm as well, is triggered by simultaneous contraction of both dorsal (DIM, DIL, DEM,DEL) and ventral (VIM, VIL, VEM,VEL) muscles. The crawling movements exhibited by the silkworm larva is accompanied by change in body shape, during which all the ventral and dorsal muscles lining the body wall contract in such a way that the body segments become rigid and as reported by David and Ananthakrishnan

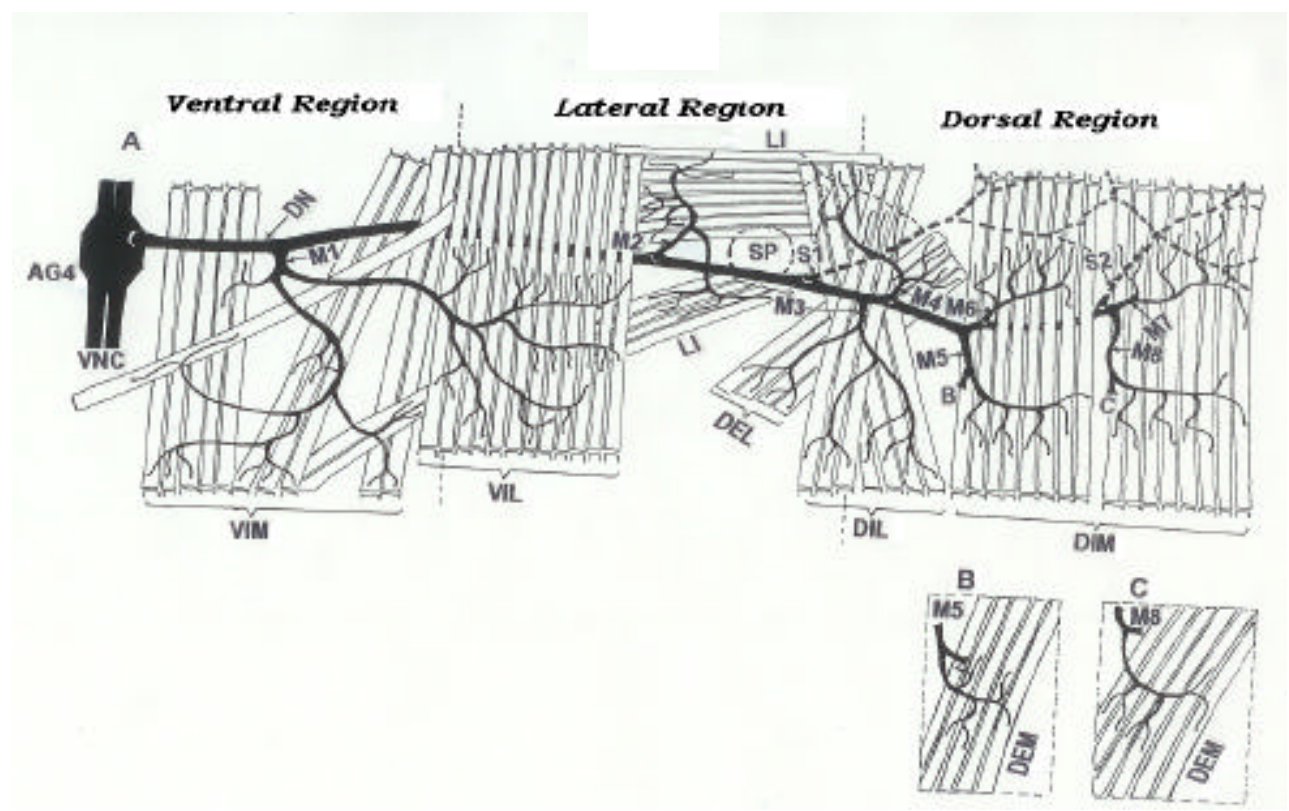

Fig. 7. (A). Musculature of the fourth abdominal hemi-segment and its innervation by the dorsal nerve (DN) of the fourth abdominal ganglion $\left(\mathrm{AG}_{4}\right)$, in the fifth instar larva of Bombyx mori. Insets $\boldsymbol{B}, \boldsymbol{C}$ : The distribution of motor branches $M_{5}$ and $M_{8}$ respectively. Remaining notations are the same as in the legend for Fig. 1. 


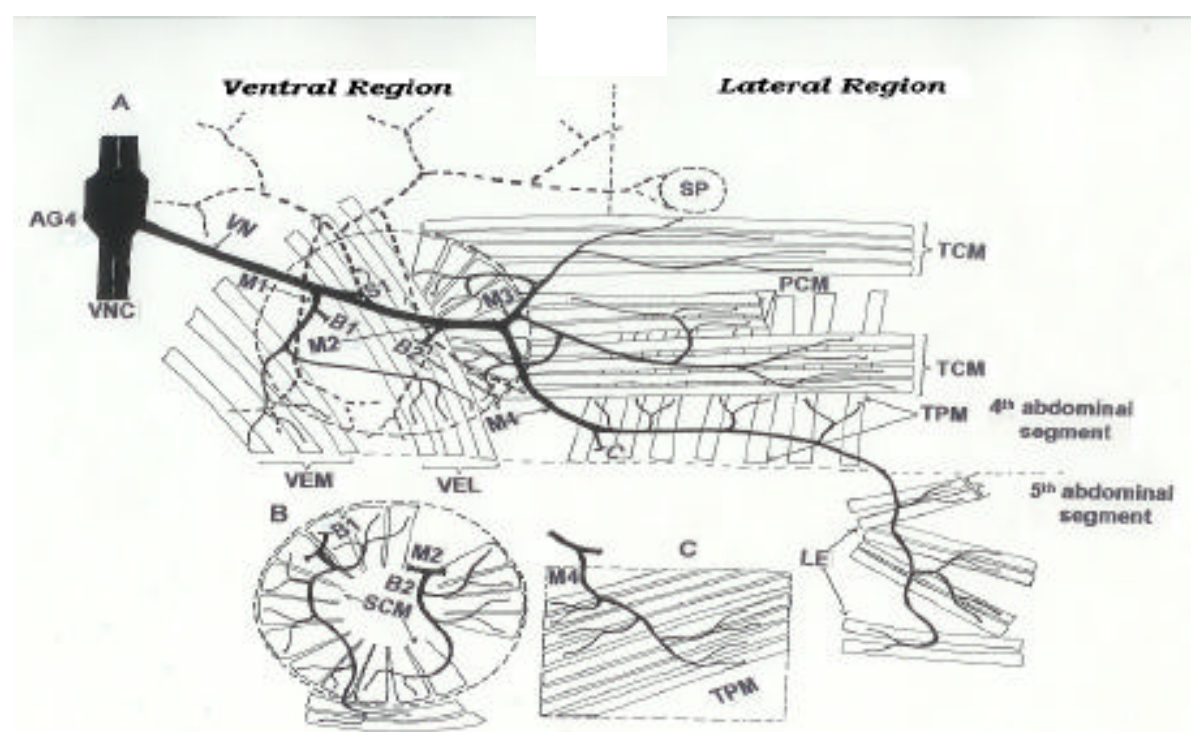

Fig. 8. Musculature of the fourth abdominal hemi-segment and its innervation by the ventral nerve (VN) of the fourth abdominal ganglion $\left(A G_{4}\right)$, in the fifth instar larva of Bombyx mori. Inset B : Arrangement of sternocoxal muscles (SCM) and their innervation by $M_{1}$ and $M_{2}$ in the coxal region of the abdominal proleg. Inset C: Distribution of $M_{4}$ PCM. pleurocoxal muscles; Remaining notations are the same as in the legends for Fig. land 2.

(2006), the change in body shape during this process is caused by hydrostatic pressure exerted by the haemolymph and other body fluids. In this mechanism, the contraction of dorsal muscles enables the larva to lift the posterior end of the segment and allows forward leg movement, while the contraction of ventral muscles brings down the segment to its normal position and facilitates firm fixation of feet to the ground.

The lateral group of muscles includes spiracular (SM), tergostenal (TSM), tergopleural (TPL), tergocoxal (TCM), pleurosternal (PSM), sternocoxal (SCM) and pleurocoxal (PCM) muscles. Most of these muscles are intrasegmental in position with an external horizontal disposition and lack internal layers, and their number ranges from 8 to 28 in abdominal segments (Table, 1). In some segments, PSM and TPM lie in intersegmental folds, while in some other segments TPM occur in the pleural area, just external to the PSM. Functionally, this group of muscles act as compressors of the body, since their contraction approximates the tergal and sternal plates (Snodgrass, 1935). Conversely, relaxation of these muscles causes inspiration by opening the spiracles in abdominal segments. According to Deshpande and Pathan (1982), most of these muscles have a dual function in insect physiology, i.e. the lifting the body above the substratum during locomotion and controlling the movement of spiracles during respiration.

The musculature in silkworm larva becomes highly complex and elaborate due to the presence of sternocoxal muscles in all proleg-bearing $3^{\text {rd }}, 4^{\text {th }}, 5^{\text {th }}$, and $6^{\text {th }}$ abdominal segments. This group, comprising 17 to 30 muscles in each hemi-segment which occurs externally with an oblique disposition in the pro-leg or in a vertical disposition near the coxa (Table 1). However, such muscles are absent in non-leg-bearing abdominal segments, which reflects the fact that the pro-leg is a true metamorphic character without any phylogenetic importance (Libby, 1959). However, this statement cannot be universally applied to all insects, since the abdominal pro-legs have an important role in causing crawling movements of caterpillars during which they firmly attach the ventral body surface to the substratum (David and Ananthakrshnan, 2006). In fact, Alsop (2005) identified 368 muscles controlling the leg movement in a cockroach and emphasized that neural control of leg musculature could have significant role in evolution of movement in insects. Though, the detailed neuromuscular architecture of pro-legs of silkworm has not been adequately examined in the present investigation, nevertheless, the projected data on abdominal musculature and its innervation throws light on some fundamental aspects of neuromuscular mechanism governing the legmovement.

Functionally, the SCM, in close association with TCM, PCM and SCM are known to effect the leg movement in insect larvae (Snodgrass, 1935). In silkworm, the pro-leg muscles help in causing walking, searching and dispersive movements during active feeding. Additionally, they act as anchorage to the substratum and provides firm grip to the silkworm larva at the time of cocoon-spinning activity, during which, the larva virtually stands on its abdominal pro-legs and lifts its entire thorax and part of abdomen above the substratum and freely rotates its anterior end. Accordingly, during these movements, the TCM attached to the anterior coxal base may act as tergal promoters of the legs and help in 


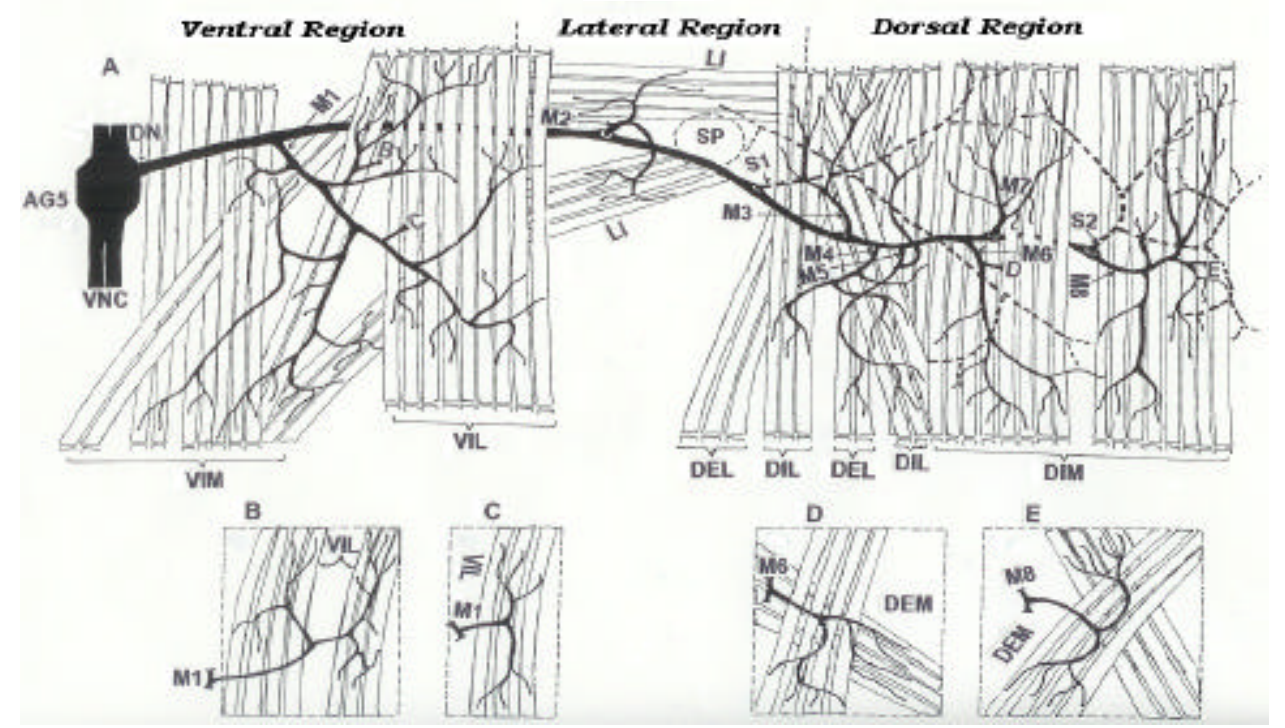

Fig. 9. (A). Musculature of the fifth abdominal hemi-segment and its innervation by the dorsal nerve (DN) of the fifth abdominal ganglion $\left(A G_{5}\right)$, in the fifth instar larva of Bombyx mori. Insets $\boldsymbol{B}, \boldsymbol{C}, \boldsymbol{D}, \boldsymbol{E}:$ The distribution of motor branches $M_{1}, M_{1}, M_{6}$ and $M_{8}$ respectively. Remaining notations are the same as in the legend for Fig. 1.

lifting the anterior half of the body from the substratum, while the SCM with similar articulations may act as sternal promoters of the prolegs and facilitate their firm attachment to the substratum in the abdominal region. Further, PCM and PSM, in association with SCM may function as coxal promoters by acting as abductors of coxa as advocated by Snodgrass (1935).

According to Snodgrass (1935) the most advanced feature of insect musculature is the presence of PCM or PSM that allows free leg movement in longitudinal, transverse and vertical planes, while the addition of TCM, TSM and TPM retards the leg movement and thus represents a very primitive feature of locomotion. Though, the presence of only two groups of muscles, viz., PSM or PCM and SCM in other pro-leg bearing segments (Figs. $6,8,10,12$ ) suggests an advanced feature of locomotion of the hinge in transversely inclined axis, the distribution of similarly disposed muscles such as TSM, TPM etc, also in the non-leg bearing segments, indicates the most primitive nature of locomotion in the silkworm, with characteristic sluggish body movements when compared to other active insects.

Innervation patterns : The innervation pattern of abdominal musculature by the branches of DN and VN of abdominal ganglia of silkworm presents certain variations with in the framework of basic innervation patterns observed in other insects (Libby, 1959; Randall, 1968 and Taylor and Truman, 1974). The following are the specific features of muscular innervations in the silkworm.

i. All the three groups of muscles, viz., ventral internals (VIM and VIL), lateral internals (LI) and both dorsal externals (DEL and DEM) and dorsal internals (DIM and
DIL) receive innervation exclusively from the DN in all the abdominal segments. The muscles such as the ventral externals (VEM and VEL) and lateral externals (TSM, PSM, TPM, TCM, SCM, PCM, SM) receive innervations from the VN only. The locomotory function caused by the contraction of dorsal and ventral muscles is obviously triggered by the collective action of DN and VN, while the ventilatory movements of spiracles are coordinated by the DN.

ii. The sternocoxal muscles of pro-legs in the $3^{\text {rd }}, 4^{\text {th }}, 5^{\text {th }}$ and $6^{\text {th }}$ abdominal segments and those involved directly or indirectly in larval movements, viz., PCM, SCM, SPM etc., receive innervations exclusively from the $\mathrm{VN}$ of all abdominal ganglia. Evidently, the central neural control mechanism of larval locomotion in silkworm is located in the ventral ganglia and it is executed through the ventral nerves of the segmental ganglia.

iii. Another noteworthy feature is the presence of multiple innervations, in which muscle bundles receive innervations from more than one motor branch of DN and VN. For example many dorsal, ventral and lateral internal muscles receive such multiple innervations from the motor branches of the DN in all abdominal segments. In such cases either different sub-branches of a motor nerve or different motor nerves innervate the same muscle bundles. Both these situations are common in silkworm (Figs. 1,3,4,5,6,7,9,11,13). They reflect the presence of fast or excitatory and slow or inhibitory axons in the nervous system of silkworm similar to that observed in a variety of insects (Usherwood, 1968; Iles and Pearson, 1969; Shepheard, 1970 and Stokeset al., 2005). However, it needs further elucidation in silkworm. 


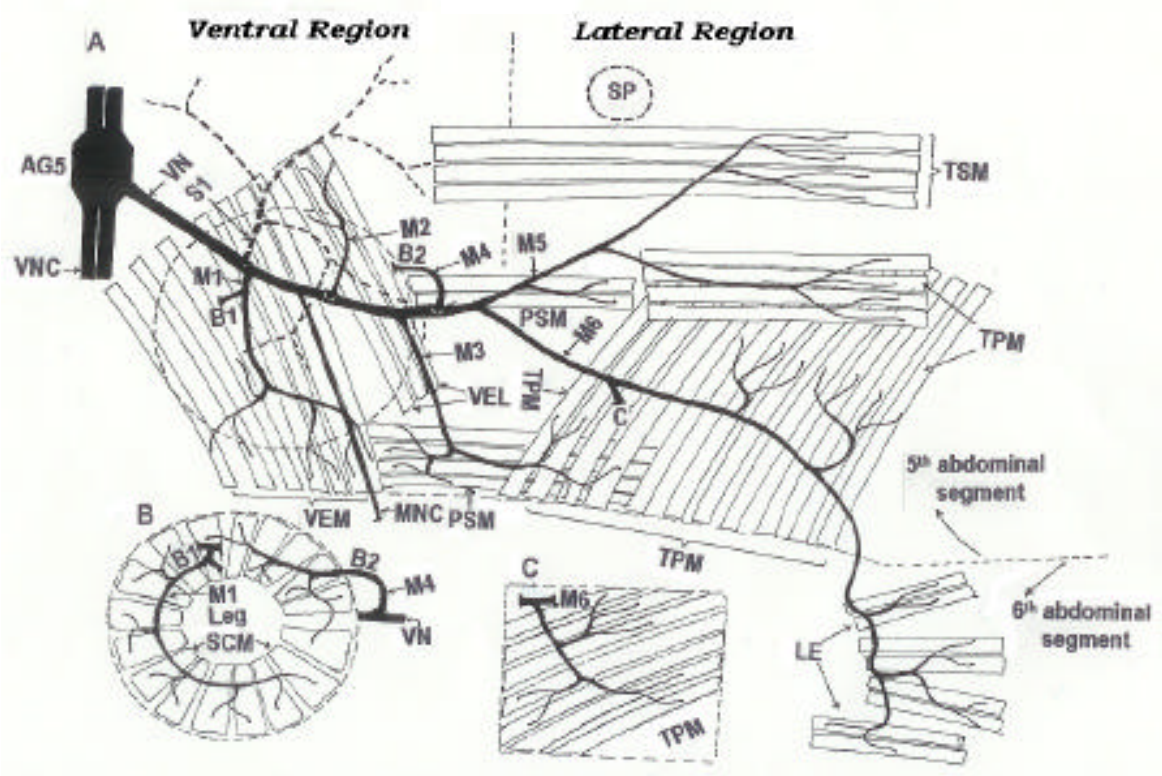

Fig. 10. Musculature of the fifth abdominal hemi-segment and its innervation by the ventral nerve $(V N)$ of the fifth abdominal ganglion $\left(A G_{5}\right)$, in the fifth instar larva of Bombyx mori. Inset B:Arrangement of sternocoxal muscles (SCM) and their innervation by $M_{1}$ and $M_{4}$ in the coxal region of the abdominal proleg. Inset $C$ : Distribution of $M_{6 .}$ PSM. pleurosternal muscles; Remaining notations are the same as in the legends for Fig. land 2.

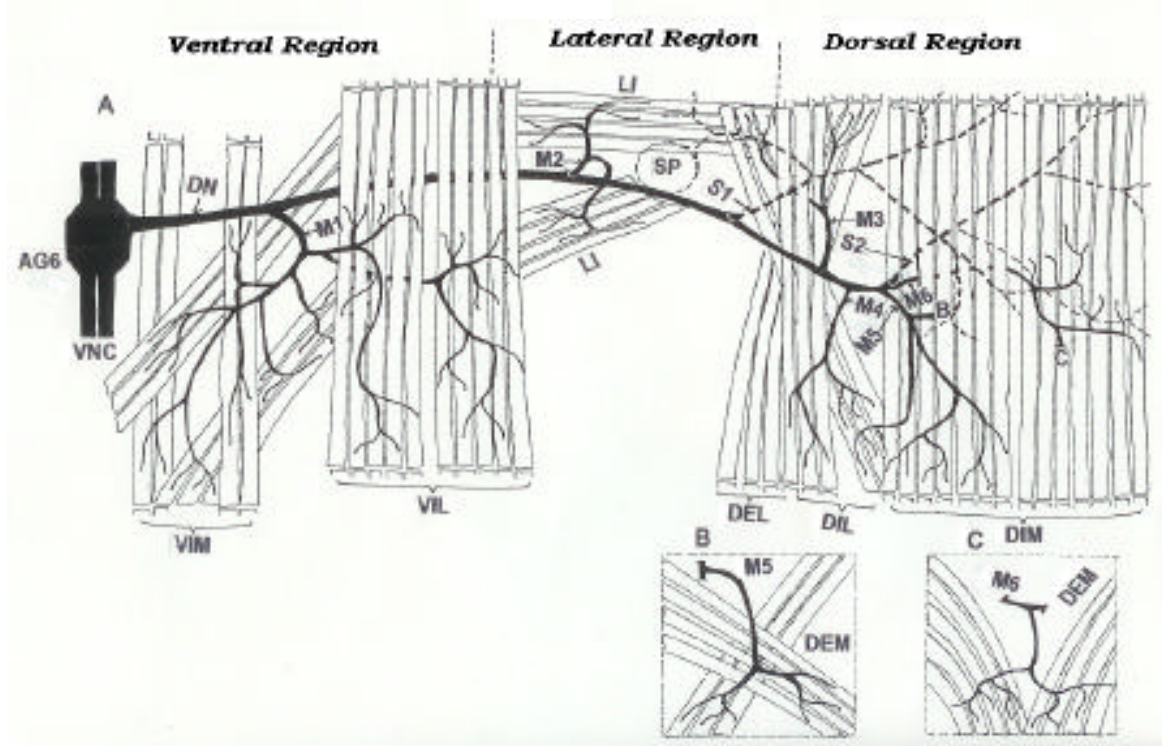

Fig. 11. (A). Musculature of the sixth abdominal hemi-segment and its innervation by the dorsal nerve (DN) of the sixth abdominal ganglion $\left(A G_{6}\right)$, in the fifth instar larva of Bombyx mori. Insets $\boldsymbol{B}, \boldsymbol{C}:$ The distribution of motor branches $M_{5}$ and $M_{6}$ respectively. Remaining notations are the same as in the legend for Fig. 1.

iv. The presence of intersegmental nerves is another interesting feature of silkworm nerve muscle coordination. As in the locust (Shepheard, 1970), the silkworm possesses certain intersegmental nerves which innervate muscles of adjacent segments. Such nerves emanate either from the DN or from the VN, either in the form of a motor branch or median nerve connective (MNC) and achieve intersegmental coordination in four different ways. The first intersegmental coordination is seen in between the thorax and abdomen and is facilitated by a small motor branch of DN of AG1, which runs in the anterior direction and extends into the preceding metathorax and courses along and innervates two large ventral muscles lying in midventral position in between two chords of the ventral nerve chord (Fig. 1). The second type of intersegmental coordination is achieved by the ventral nerves of $\mathrm{AG}_{2}$ (Fig.4), $\mathrm{AG}_{4}$ (Fig. 8), $\mathrm{AG}_{5}$ (Fig. 10) which give an intersegmental motor branch that extends 


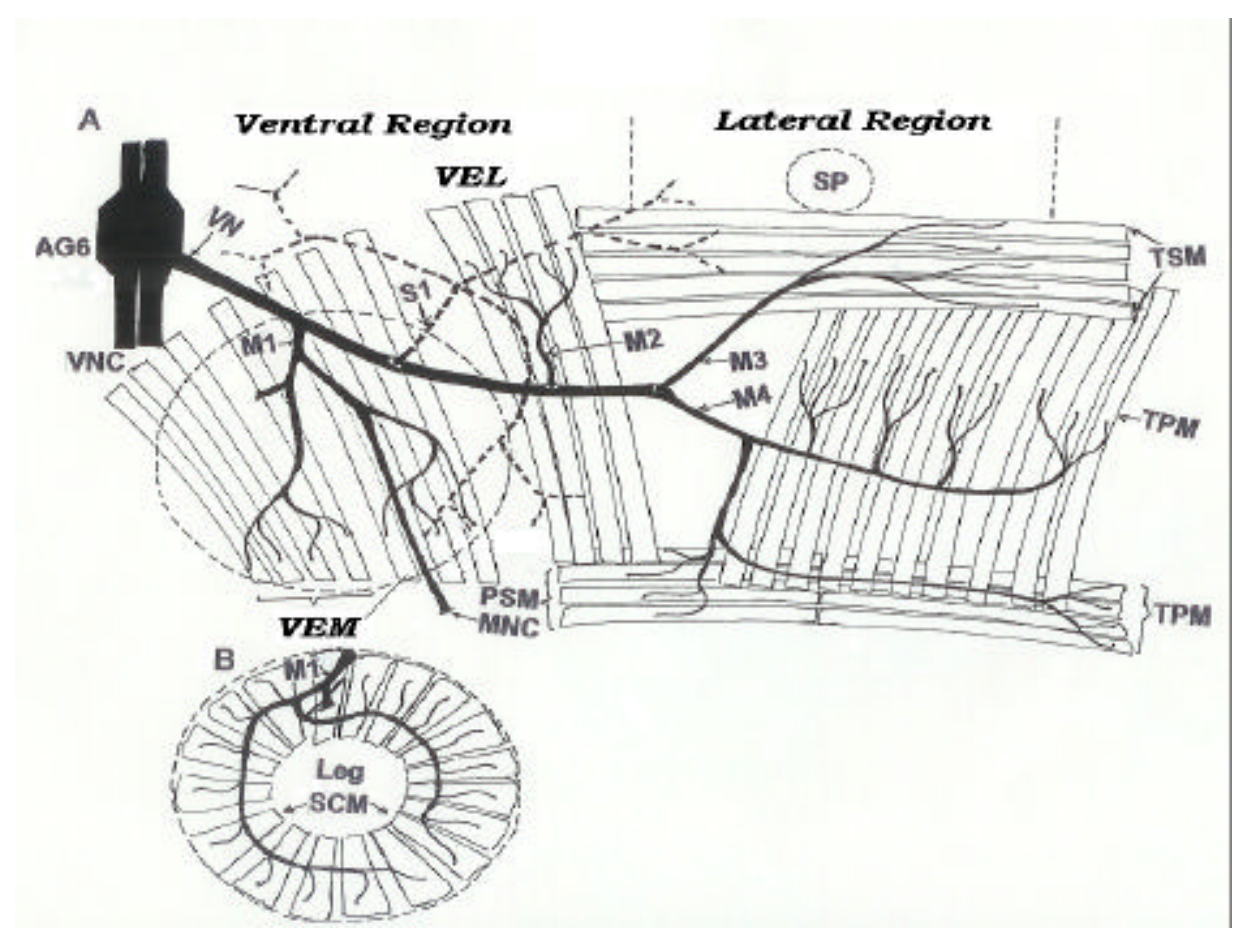

Fig. 12. Musculature of the sixth abdominal hemi-segment and its innervation by the ventral nerve (VN) of the sixth abdominal ganglion $\left(A G_{6}\right)$, in the fifth instar larva of Bombyx mori. Insets $\boldsymbol{B}:$ Arrangement of sternocoxal muscles (SCM) and their innervation by $M_{1}$ in the coxal region of the abdominal proleg. Inset C: Distribution of $M_{6}$ PSM. pleurosternal muscles;

Remaining notations are the same as in the legends for Figs. land 2. Note: An intersegmental nerve designated median nerve connective $(M N C)$ arises from the $M 1$ which extends into the next segment.

into and innervates lateral external muscles or musculi lateralis externi (LE) in the third, fifth and sixth abdominal segments. The third type of intersegmental coordination is facilitated by the participation of entire nerves, viz., the $\mathrm{DN}, \mathrm{VN}$ and $\mathrm{CN}$ of the $8^{\text {th }}$ abdominal ganglion which originate actually in the seventh abdominal segment from the confluent $\mathrm{AG}_{8}$, which then extend into the ganglionless eighth abdominal segment and innervates all segmental muscles or body wall there (Figs. 15, 16,17). The fourth type of intersegmental coordination is facilitated by the median nerve connectives (MNC) originating either from the DN or VN of abdominal ganglia. For instance, a MNC arises from the motor branch of $\mathrm{DN}$ of $\mathrm{AG}_{1}$ and joins the transverse nerve (TN) of the median nerve $(\mathrm{MN})$ and innervates selected ventral muscles in the metathorax (Fig.1). Similarly, the VN of $\mathrm{AG}_{1}, \mathrm{AG}_{3}, \mathrm{AG}_{5}$ and $\mathrm{AG}_{6}$ give median nerve connectives that extend in between $1^{\text {st }}$ and $2^{\text {nd }}$ (Fig. 2), 3rd and $4^{\text {h }}$ (Fig. 6), 5th and $6^{\text {th }}$ (Fig. 10) and in between $6^{\text {th }}$ and $7^{\text {th }}$ (Fig. 12) abdominal segments where their motor branches innervate some lateral intersegmental muscles (LE) in association with the $\mathrm{TN}$ of respective median nerves (not shown in Fig.).

v. The significant aspect of neuromuscular integration in the silkworm obviously, is the presence of a bidirectional arrangement of intersegmental nerves in which they extend in opposite directions in the thorax and abdomen. For instance, one such intersegmental motor branch extends from the first abdominal segment into the metathorax (Fig.1). Conversely, such branches extend from a previous segment to the next segment in the abdomen (Figs. 4, 8). Such an arrangement could ensure approximation of adjacent segments in the thorax and abdomen during locomotion in which a wave of peristalsis passes over the larval body. Barth (1937), demonstrated that peristalsis in the insect larval body involves simultaneous contraction of at least three segments. But the arrangement of intersegmental nerves in silkworm suggests that the peristalsis involves the simultaneous contraction of muscles in at least two segments. Clearly, in silkworm the coordinated activity of thorax and abdomen and that of individual segments is monitored by the central nervous system through segmental and intersegmental nerve branches of DN and VN. The combined action of these two nerves could help in causing stiffness of abdominal segments due to contraction of dorsal group of muscles and relaxation of ventral group of muscles, that could provide the tensile strength required for pumping of haemolymph and for opening and closing of the spiracles for effective ventilation during respiration as reported in certain locusts (Ramirez and Pearson, 1989; Youssef, 2005 a, b). Such an integrated mechanism enhances physical strength of the body for effective cocoon-spinning activity by the silkworm larvae at the end fifth instar. vi. The number of motor branches of $\mathrm{DN}$ and $\mathrm{VN}$ seems 


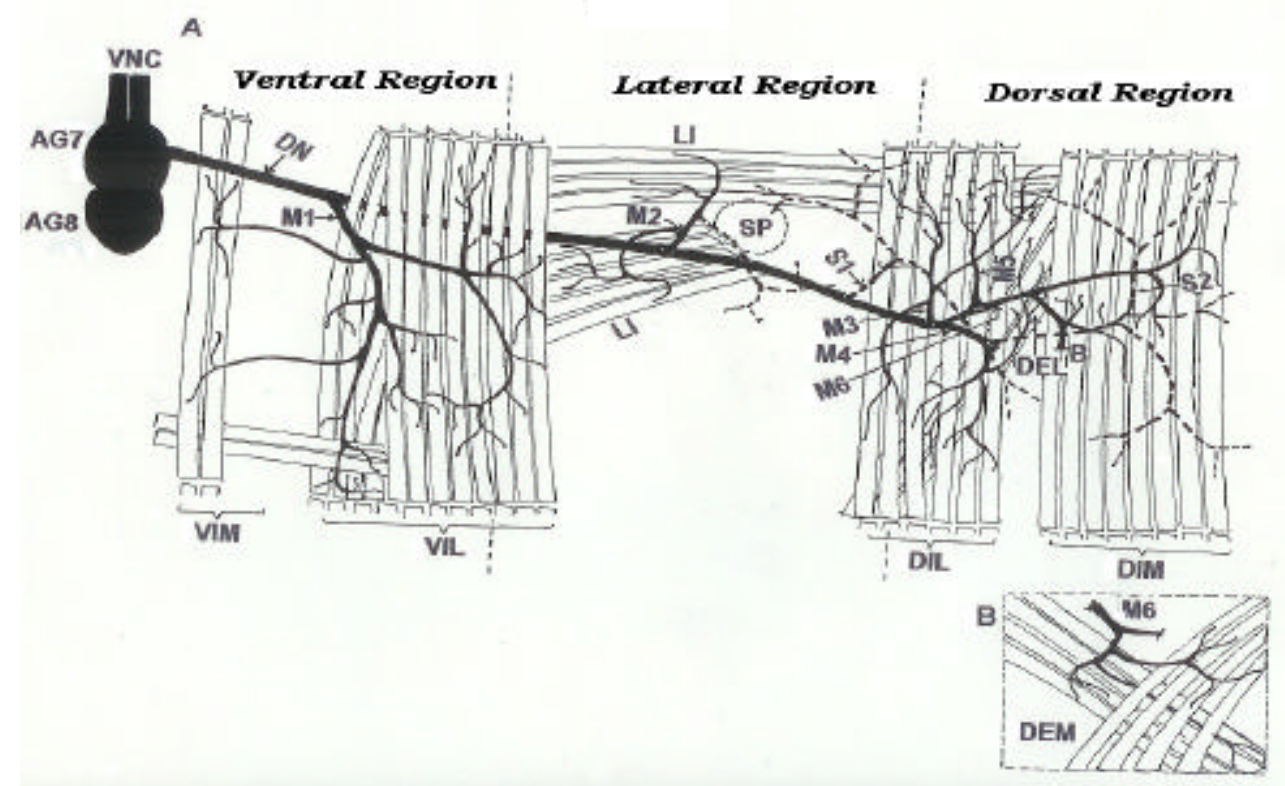

Fig. 13. (A). Musculature of the seventh abdominal hemi-segment and its innervation by the dorsal nerve (DN) of the seventh abdominal ganglion $\left(A G_{7}\right)$, in the fifth instar larva of Bombyx mori. Inset B: The distribution of motor branch $M_{6}$. Remaining notations are the same as in the legend for Fig. 1.

Table 1. Distribution of Muscles in the eight abdominal ganglia (AG1 to AG8) of the fifth instar larva of the silkworm, Bombyx mori. The number of abdominal muscles were shown region-wise, layer-wise (external / internal) and segment- wise separately. The number of SCM in the leg-bearing segments is also shown.

\begin{tabular}{|c|c|c|c|c|c|c|c|c|}
\hline \multirow[t]{2}{*}{ Segment } & \multicolumn{3}{|c|}{$\begin{array}{l}\text { No of muscles: } \\
\text { region-wise }\end{array}$} & \multicolumn{2}{|c|}{$\begin{array}{l}\text { No. of muscles: } \\
\text { layer-wise }\end{array}$} & \multirow{2}{*}{$\begin{array}{l}\text { No. of SCM in } \\
\text { leg-bearing } \\
\text { segments }\end{array}$} & \multicolumn{2}{|c|}{$\begin{array}{l}\text { No. of muscles: } \\
\text { segment -wise }\end{array}$} \\
\hline & ventral & lateral & dorsal & internal & external & & hemi -segment & full Segment \\
\hline $\mathrm{AS}-1$ & 34 & 36 & 43 & 51 & 62 & - & 113 & 226 \\
\hline AS - 2 & 58 & 36 & 44 & 60 & 78 & - & 138 & 276 \\
\hline AS - 3 & 45 & 35 & 38 & 64 & 54 & 30 & 148 & 296 \\
\hline $\mathrm{AS}-4$ & 31 & 38 & 38 & 60 & 47 & 26 & 133 & 266 \\
\hline AS - 5 & 43 & 36 & 45 & 65 & 59 & 17 & 141 & 282 \\
\hline AS - 6 & 31 & 31 & 39 & 48 & 53 & 18 & 119 & 238 \\
\hline AS -7 & 28 & 30 & 25 & 38 & 45 & - & 83 & 166 \\
\hline AS -8 & $35^{*}$ & 08 & 10 & 25 & $28 *$ & - & 53 & 106 \\
\hline Total & 305 & 250 & 282 & 411 & 426 & 91 & 928 & 1856 \\
\hline
\end{tabular}

* Includes 6 pyloric muscles and 18 cercal muscles, counted as ventral externals.

AS1 to AS8 = Abdominal segments 1 to 8 . 


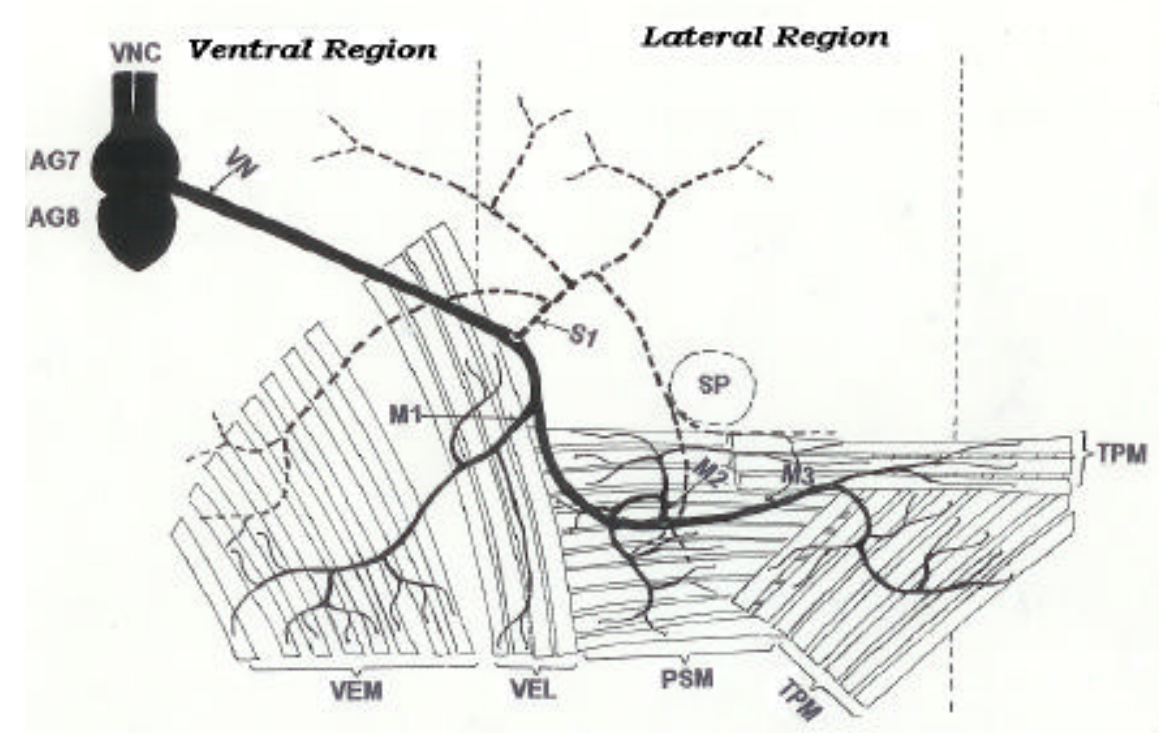

Fig. 14. Musculature of the seventh abdominal hemi-segment and its innervation by the ventral nerve (VN) of the seventh abdominal ganglion $\left(A G_{7}\right)$, in the fifth instar larva of Bombyx mori. Remaining notations are the same as in the legends for Figs. 1 and 2.

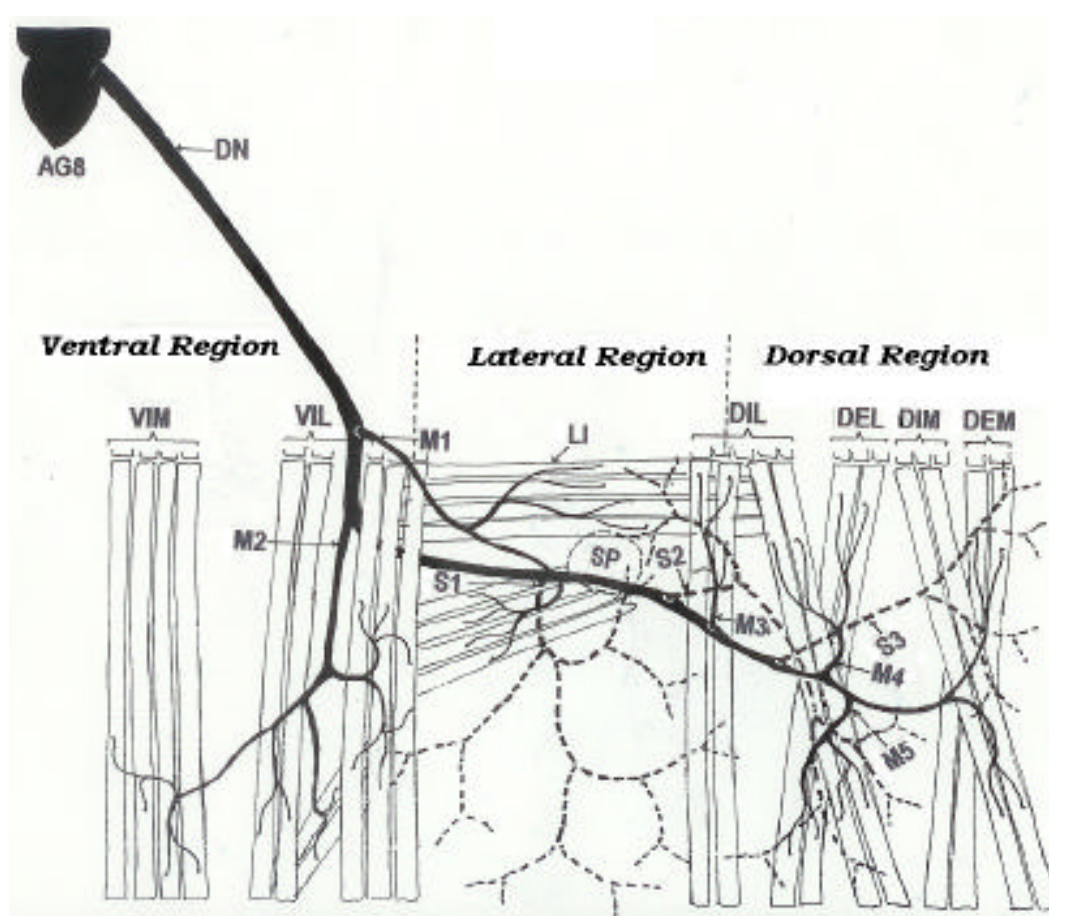

Fig. 15. (A). Musculature of the eighth abdominal hemi-segment and itsinnervation by the dorsal nerve (DN) of the eighth abdominal ganglion $\left(A G_{8}\right)$, in the fifth instar larva of Bombyx mori. Remaining notations are the same as in the legend for Fig. 1.

to vary as a function of number of muscles innervated and the complexity of musculature. With a few exceptions ( $\mathrm{VN}$ of $\mathrm{AG}_{2}, \mathrm{AG}_{4}$ and $\mathrm{AG}_{5}$ ), the greater the number of muscles present in the given area of the segment, the greater will be the number of branches and vice versa. Thus, the DN sends 4 to 9 motor branches in the dorsal region where they innervate both internal and external layers of muscles, and four branches in the ventral region where it innervates only the external layers.

vii. The origin and distribution of sensory branches follow a specific rule in silkworm. The sensory branches of DN arise only in the lateral and dorsal regions of the segment and they innervate those two regions only. On the other hand the sensory branches of VN originate only in the ventral region of the segment and innervates that particular region. 
Table 2. Branching and innervation patterns of the dorsal (DN) and ventral (VN) nerves of the ganglionic nerves of the eight abdominal ganglia (AG1 to AG8) in the fifth instar larva of the silkworm, Bombyx mori. The number of motor and sensory branches, the muscles innervated by the motor branches, the area innervated by the sensory branches in each hemi-segment and the nature of the nerve are also shown .

\begin{tabular}{|c|c|c|c|c|c|c|}
\hline \multirow{2}{*}{ Ganglion } & \multirow{2}{*}{ Nerve } & \multicolumn{2}{|r|}{ Motor branches } & \multicolumn{2}{|c|}{ Sensory branches } & \multirow{2}{*}{$\begin{array}{l}\text { Nature of } \\
\text { the nerve }\end{array}$} \\
\hline & & Number & Muscles innervated & Number & Area innervated & \\
\hline $\mathrm{AG}_{1}$ & $\mathrm{DN}$ & $9\left[\mathrm{M}_{1}-\mathrm{M}_{9}\right]$ & $\begin{array}{l}8 \text { VIM, } 12 \text { VIL, } 8 \text { DIL, } 8 \text { LI, } 8 \text { DEL, } \\
20 \text { DEM,15 DIM \& } 2 \text { VM in } \\
\text { metathorax. }\end{array}$ & $3\left[\mathrm{~S}_{1^{-}} \mathrm{S}_{3}\right]$ & $\begin{array}{l}\text { VR,VLR, DLR, } \\
\text { DR, MDR }\end{array}$ & Mixed nerve \\
\hline \multirow{3}{*}{$\mathrm{AG}_{2}$} & VN & $4\left[\mathrm{M}_{1}-\mathrm{M}_{4}\right]$ & 8VEM,6VEL,11TSM,6PSM,11TPM & $1\left[\mathrm{~S}_{1}\right]$ & MVR, VLR, LR & Mixed nerve \\
\hline & $\mathrm{DN}$ & $8\left[M_{1}-M_{8}\right]$ & $\begin{array}{l}11 \mathrm{VIM}, 20 \mathrm{VIL}, 8 \mathrm{LI}, 7 \mathrm{DIL} \text {, } \\
7 \text { DEL, 14DIM, 16DEM }\end{array}$ & $3\left[S_{1^{-}} S_{3}\right]$ & $\begin{array}{l}\text { VR, DLR, DR, } \\
\text { MDR }\end{array}$ & Mixed Nerve \\
\hline & VN & $6\left[M_{1}-M_{6}\right]$ & $\begin{array}{l}\text { 17VEM, 10VEL, 4TSM, } 8 \text { PSM, } 16 \\
\text { TPM, and } 7 \text { PCM \& } 8 \text { LE in AS- } 3\end{array}$ & $1\left[\mathrm{~S}_{1}\right]$ & MVR, VLR, LR & Mixed Nerve \\
\hline \multirow[t]{2}{*}{$\mathrm{AG}_{3}$} & $\mathrm{DN}$ & $6\left[\mathrm{M}_{1}-\mathrm{M}_{6}\right]$ & $\begin{array}{l}16 \text { VIM, } 17 \text { VIL, } 8 \text { LI, } 7 \text { DIL, } \\
\text { 7DEL, } 16 \text { DIM, } 8 \text { DEM. }\end{array}$ & $2\left[\mathrm{~S}_{1-} \mathrm{S}_{2}\right]$ & DLR, MDR & Mixed nerve \\
\hline & VN & $4\left[\mathrm{M}_{1}-\mathrm{M}_{4}\right]$ & $\begin{array}{l}8 \text { VEM, 4VEL, } 30 \text { SCM, } 5 \text { PSM, } \\
22 \text { TPM }\end{array}$ & $1\left[S_{1}\right]$ & MVR, VR, VLR & Mixed nerve \\
\hline \multirow[t]{3}{*}{$\mathrm{AG}_{4}$} & $\mathrm{DN}$ & $8\left[\mathrm{M}_{1}-\mathrm{M}_{8}\right]$ & $\begin{array}{l}13 \text { VIM, 12VIL, } 12 \text { LI, } 4 \text { DEL, } \\
7 \text { DIL, } 11 \text { DEM, } 16 \text { DIM }\end{array}$ & $2\left[S_{1}, S_{2}\right]$ & DLR, MDR, DR & Mixed nerve \\
\hline & $\mathrm{VN}$ & $4\left[\mathrm{M}_{1}-\mathrm{M} 4\right]$ & $\begin{array}{l}3 \text { VEL, 3VEM, } 26 \text { SCM, 8TCM, } \\
\text { 3PCM, } 15 \text { TPM \& } 8 \text { LE in AS -5 }\end{array}$ & $1\left[\mathrm{~S}_{1}\right]$ & MVR, VR,VLR & Mixed nerve \\
\hline & $\mathrm{DN}$ & $8\left[\mathrm{M}_{1}-\mathrm{M}_{8}\right]$ & $\begin{array}{l}\text { 14VIM, 19VIL, } 8 \text { LI, } 8 \text { DIL, } 5 \text { DEL, } \\
16 \text { DEM, } 16 \text { DIM }\end{array}$ & $2\left[\mathrm{~S}_{1}, \mathrm{~S}_{2}\right]$ & DLR,MDR,DR & Mixed nerve \\
\hline $\mathrm{AG}_{5}$ & VN & $6\left[M_{1}-M_{6}\right]$ & $\begin{array}{l}\text { 7VEM, 3VEL, } 17 \text { SCM, } 6 \text { PSM, } \\
18 \text { TPM, } 4 \text { TSM \& } 8 \text { LE in AS-6. }\end{array}$ & $1\left[S_{1}\right]$ & MVR,VLR,VR & Mixed nerve \\
\hline \multirow[t]{2}{*}{$\mathrm{AG}_{6}$} & $\mathrm{DN}$ & $6\left[\mathrm{M}_{1}-\mathrm{M}_{6}\right]$ & $\begin{array}{l}\text { 10VIM, 10VIL, } 8 \text { LI, } 3 \text { DEL, } 6 \text { DIL, } \\
16 \text { DEM, } 14 \text { DIM. }\end{array}$ & $2\left[\mathrm{~S}_{1}, \mathrm{~S}_{2}\right]$ & DLR,MDR,DR & Mixed nerve \\
\hline & VN & $4\left[\mathrm{M}_{1}-\mathrm{M} 4\right]$ & $\begin{array}{l}7 \text { VEM, 4VEL, } 18 \text { SCM, } 5 \text { TSM, } \\
4 \text { PSM, } 14 \text { TPM }\end{array}$ & $1\left[\mathrm{~S}_{1}\right]$ & MVR,VLR,VR & Mixed nerve \\
\hline \multirow[t]{2}{*}{$\mathrm{AG}_{7}$} & DN & $6\left[\mathrm{M}_{1}-\mathrm{M}_{6}\right]$ & $\begin{array}{l}4 \text { VIM, } 12 \text { VIL, } 8 \text { LI, } 6 \text { DIL, 3DEL, } \\
8 \text { DEM, } 8 \text { DIM }\end{array}$ & $2\left[\mathrm{~S}_{1}, \mathrm{~S}_{2}\right]$ & DLR,MDR,DR & Mixed nerve \\
\hline & VN & $3\left[\mathrm{M}_{1}-\mathrm{M}_{3}\right]$ & 8 VEM, 4 VEL, 11TPM, 11 PSM & $1\left[S_{1}\right]$ & MVR,VLR,VR & Mixed nerve \\
\hline \multirow[t]{3}{*}{$\mathrm{AG}_{8}$} & $\mathrm{DN}$ & $5\left[\mathrm{M}_{1}-\mathrm{M}_{5}\right]$ & $\begin{array}{l}4 \text { VIM, } 7 \text { VIL, } 8 \text { LI, } 4 \text { DIL, 2DEL, } \\
2 \text { DIM, } 2 \text { DEM }\end{array}$ & $3\left[S_{1}-S_{3}\right]$ & $\begin{array}{l}\text { VR,VLR,DR,DLR, } \\
\text { MDR }\end{array}$ & Mixed nerve \\
\hline & $\mathrm{VN}$ & $4\left[\mathrm{M}_{1}-\mathrm{M} 4\right]$ & $6 \mathrm{PM}, 18 \mathrm{CM}$ & $1\left[S_{1}\right]$ & MVR,VLR,VR & Mixed nerve \\
\hline & $\mathrm{CN}$ & --- & --- & - & VR, VLR,DR & $\begin{array}{l}\text { Sensory } \\
\text { nerve }\end{array}$ \\
\hline
\end{tabular}

$\mathrm{AG}_{1} \mathrm{TO} \mathrm{AG}_{8}$. First to eighth abdominal ganglia; AS. abdominal segment; CM. cercal muscles; CN. cercal nerve; DEL. musculi dorsales externi laterales; DEM. musculi dorsales externi mediales; DIL. musculi dorsales interni laterales; DIM. musculi dorsales interni mediales; DLR. dorsolateral region; DM. dorsal muscles; DN. dorsal nerve; DR.dorsal region; LE. musculi externi laterales; LI. musculi interni laterales;LR. lateral region; M 1 - M 9. 1st to 9th motor nerves; MDR. mid-dorsal region; MNC. median nerve connective; MVR. midventral region; PCM. Pleurocoxal muscles; PM. pyloric muscles; PSM. Pleurosternal muscles; SCM. sternocoxal muscles; SM. spiracular muscles; TCM. tergocoxal muscles; TPM. tergopleural muscles; TSM.. tergosternal muscles; VEL.musculi ventrales externi laterales; VEM. musculi ventrales externi mediales; VIL. musculi ventrales interni laterals; VIM. musculi ventrales interni mediales; VLR. ventrolateral region; VM. ventral muscles; VN. ventral nerve; VR. ventral region.

viii. Though, the territory of the sensory branches is restricted, often there exists a sort of overlap between the branches of $\mathrm{VN}$ and $\mathrm{DN}$ in the lateral region of the segment. Such an arrangement facilitates the entry of sensory input either through the DN or VN. Hence, it appropriate to suggest that, the sensory branches of DN receive sensory information also from the ventrolateral region of the segment in addition to dorsal and dorsolateral regions. Likewise, those of $\mathrm{VN}$ receive sensory inputs from ventrolateral and lateral regions in 


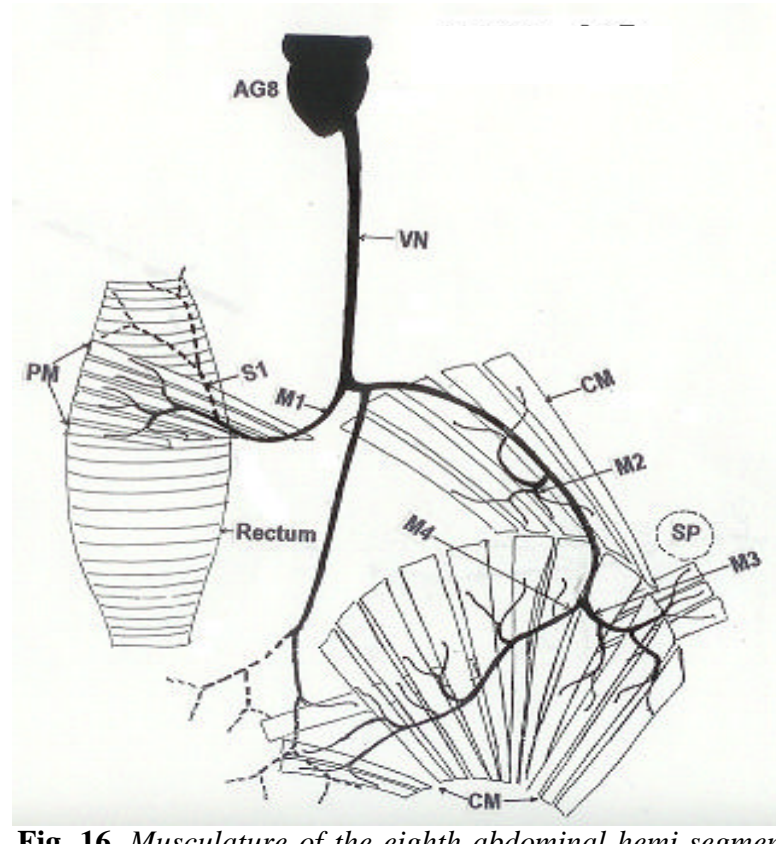

Fig. 16. Musculature of the eighth abdominal hemi-segment and its innervation by the ventral nerve (VN) of the eighth abdominal ganglion $\left(A G_{8}\right)$, in the fifth instar larva of Bombyx mori. CM. cercal muscles; PM. pyloric muscles. Remaining notations are the same as in the legends for Figs. 1and 2.

addition to the ventral region of the segment. The morphological and physiological studies on Manduca sexta (Taylor and Truman, 1974) substantiate this point of view. ix. Further, the cercal nerve with its sensory ramifications in the eighth abdominal segment collects sensory inputs throughout the segment. The important role of sensory fibres of DN, VN or $\mathrm{CN}$ is not clearly established. However, it may be presumed that they perceive sensory inputs pertaining to chordotonal organs or mechanoreceptors which are distributed throughout the body. More significantly, the sensory nerves play a key role in sound reception and transduction through the chordotonal organs (Yack, 2004).

It may be concluded that, the neuromuscular integrative mechanism observed in Bombyx mori is in agreement with similar studies made on the Cecropia silkmoth and that present in other hexapod insects (Libby, 1959). The homology in neuromuscular patterns suggest that the silkworm and other holometabolous lepidopteran insects have a common phylogenetic origin from the stock of immature forms of hemimetabolus orthopterans as presumed by Libby (1959).

\section{ACKNOWLEDGEMENTS}

Dr.S.Sivaprasad thanks the University Grants Commission (SERO), Hyderabad, for financial assistance through minor research project. The authors also thank Prof. P.N.R. Usherwood, Nottingham University, U. K for reading through the manuscript and offering helpful suggestions.

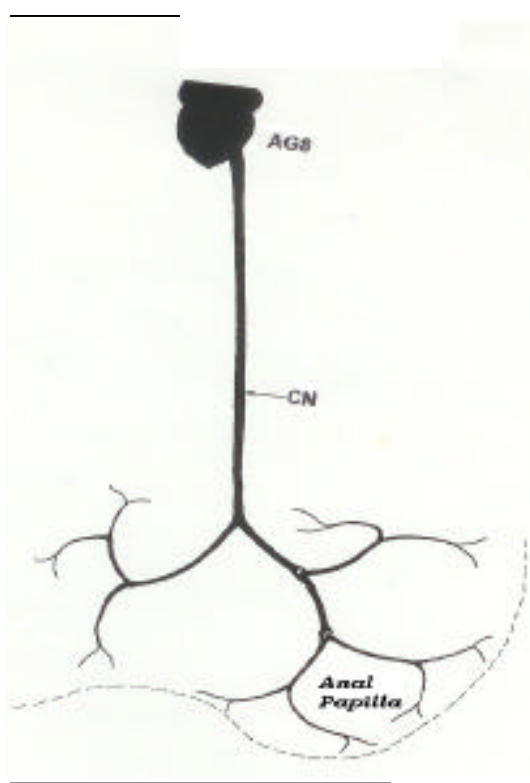

Fig. 17. Branching and innervation pattern of sensory branches of the cercal nerve $(C N)$ of the eighth abdominal ganglion $\left(A G_{8}\right)$, in the eighth abdominal hemi-segment of the fifth instar larva of Bombyx mori. CM. cercal muscles; PM. pyloric muscles. Remaining notations are the same as in the legends for Fig. land 2.

\section{REFERENCES}

Alsop, D.W. (2005). Comparative analysis of the intrinsic leg musculature of the American cockroach, Periplaneta Americana (L.). J. Morphol., 158 (2): 199 - 241.

Barth, R. (1937). Masculatur und Bewegungsart der Reupen. Zool. Jahrb., 62: 507-566.

Bartos, M. and Honegger, H.W. (1992). Complex innervation of three neck muscles by motor and dorsal unpaired median neurons in crickets. Cell and Tissue Research., 267 (2): 399- 406.

Brunn, D.E. (1998). Cooperative mechanism between leg joints of Carausius morosus I.Non-spiking interneurons that contribute to interjoint coordination. J. Neurophysiol.,79: 2964 - 2976.

Bullaro, M. and Prete, F.R. (1999). Thoracic and prothoracic neuromuscular system of the preying mantid, Sphodromantis lineola (burmeister). J.Comp.Neurol., 409(2): $325-338$.

Burrows, M. (2007). Anatomy of the hind legs and action of their muscles during jumping in leafhopper insects. J. Exp. Biol., 210: 3590 - 3600.

Chauthani, A. R. and Callahan, P.S. (1966). A dissection technique for studying internal anatomy of different stadia of Noctidae. Ann .Entomol . Soc. Am.,59: 1017- 1018.

Copenhaver, P.F. (2007). How to innervate a simple gut: familiar themes and unique aspects in the formation of the insect enteric nervous system. Dev. Dynamics., 236 (7): 18411864.

David, B.V. and Ananthakrishnan, T.N. (2006). General and Applied Entomology New Delhi: Tata McGRaw - Hill Publishing Company Ltd.,89-102.

Davis, N.T. (2005). Serial homologies of the motor neurons of 
the dorsal intersegmental muscles of the cockroach, Periplaneta Americana(L.). J. Morphol., 176 (92): 197-210.

Denburg, J.L. and Fulop, Z. (2005). Formation of leg neuromuscular system in embryos of the cockroach, Periplaneta Americana. J.Exp.Zool., 219 (3): 323- 338.

Deshpande, S.B. and Pathan, K.M. (1982). On the pregenital abdominal muscular system in nymphal and adult Heptagenia diabasia, Burks (Ephemeroptera). J. Anim. Morphol. Physiol., 29: 272 - 279.

Duve, H., East, P. D., and Thorpe, A.(1999). Regulation of lepidopteran foregut movement by allostatins and allatotropin from the frontal ganglion. J.Comp. Neurol. , 413(3): $405-416$.

Eaton, J.L. (1982). Exoskeleton and muscular morphology of the larval thorax of Manduca sexta (Lepidoptera: Sphingidae). Ann.Entomol. Soc. Am.,75: 313 - 322.

Honegger, H.W., Altman, J.S., Klen, J., Muller-Tauz, R., and Pollerberg, E.(2004). A comparative study of neck muscle motor neurons in a cricket and a locust.J.Comp.Neurology., 230 (4): $517-535$

Iles, J. F. and Pearson, K.G. (1969) Triple inhibitory innervation of insect muscle. J. Physiol., (Lond.)., 204: 125 - 126.

Kawasaki, F. and Kita, H. (2004). Structure and innervation of longitudinal and transverse abdominal muscles of the cricket, Gryllus bimaculatus. J.Comp.Neurol., 352(1): 134 -146.

Kent, K.S. and Levine, R.B.(2004). Neural control of leg movements in a metamorphosing insect: Persistence of larval leg motor neurons to innervate the adult legs of Manduca sexta. J. Comp. Neurol., 276 (1): 30 -43.

Klass, K.D. (2008). The pregenital abdomen of a mantid and a cockroach: Musculature and nerve topography, with comparative remarks on other neoptera (Insecta:

Dictyoptera). Deutsche Entamologische Zeitschrift., 46(1): 3-42.

Kondoh, Y. and Obara, Y. (1982). Anatomy of motor neurons innervating mesothoracic indirect flight muscles in the silkmoth, Bombyx mori. J. Exp. Biol.,98: 23-37.

Kreiss, S., Schulte,C.C., Agricola, H.J. and Rathmayer, W. (1999). A single attatostatin- immunoreactive neuron innervates skeletal muscles of several segments in the locust. J.Comp. Neurol.,413 (4): 507-519.

Krishnaswami, S. (1986). New technology of silkworm rearing. Mysore ,India: Central Sericultural Research and Training Institute..

Libby, J. L. (1959). The nervous system of certain abdominal segments of the Cecropia larva (Lepidoptera: Saturnidae). Ann. Ent. Soc. Amer., 52: 469-480.

Masuko, K. (2005). Motor innervation and proprioceptors of the mouth parts in the worker honey bee Apis mellifera. II. Maxillary and labial nerves. J. Morphol., 201(1): 23 -37.

Owen, W.B.(2006). Morphology of the abdominal skeleton and muscles of the mosquito, Culiseta inormata (Wilson) (Diptera: Culicidae). J. Morphol., 166 (2): 155-178.

Ramirez, J.M. and Pearson,K.G. (1989). Alteration of the respiratory system at the onset of locust flight: I. Abdominal pumping. J.Exp.Biol., 142: 401 - 424.

Randall, W.C. (1968). Anatomical changes in the neuromuscular complex of the proleg of Galleria mellonella.L (Lepidoptera : Pyralididae) during metamorphosis. J. Morphol., 125: $105-128$.
Ready, N.E. and Josephson, R.K. (2005 a). Flight muscle development in a hemi- metabolous insect. J.Exp.Zool., 220 (1): 49 - 56.

Ready, N.E. and Josephson, R.K. (2005 b). Structural and functional development of cricket wing muscles. J.Exp.Zool., 233 (1): 35 - 50.

Shankland, D.L. (2005). Nerves and muscles of the pregenital abdominal segments of the American cockroach, Periplaneta americana (L.). J. Morphol. 117(3): 353 - 385.

Shepheard, P. (1970). Control of head movement in the locust Schistocerca gregaria. Ph.D Thesis. Univrsity of St. Andrews.

Sink, H. (2006). Muscle Development in Drosophila. Springer Publishers.

Sivaprasad, S. and Muralimohan, P. (1998). Morphological changes in the nervous system of silkworm, Bombyx mori L. (Lepidoptera : Bombycidae) during metamorphosis. Indian J. Seric., 37 (1): $21-28$.

Snodgrass, R.E. (1935). In Principles of Insect Morphology. McGraw-Hill Book Company Inc. New York.

Snodgrass, R. E. (1958). Evolution of arthropod mechanisms. Smithsonian. Misc. Coll., 138.

Spieb, R., Schoofs, A. and Heinzel, H.G. (2007). Anatomy of the stomatogastric nervous system associated with the foregut in Drosophila melanogaster and Calliphora vicina third instar larvae. J. Morphol. ,269(3): 272 - 282.

Stokes, D.R., Josephson, R.K. and Price, R.B. (2005). Structural and functional heterogeneity in an insect muscle. J. Exp. Zool., 194(2): 379- 407.

Taylor,H.M. and Truman, J.W.(1974). Metamorphosis of the abdominal ganglia of the tobacco hornworm, Manduca sexta: Changes in the populations of identified motoneurons. J. Comp. Physiol., 90: 367 - 388.

Usherwood, P.N.R. (1967). Insect neuromuscular mechanisms. Am. Zool., 7: 553 - 582.

Usherwood, P.N.R. (1968). A critical study for the evidence for peripheral inhibitory axons in insects. J. Exp. Biol., 49: $201-222$

Wolf, H. and Harzsch, S. (2002). Evolution of arthropod neuromuscular system-1. Arrangement of muscles and innervation in the walking legs of a scorpion, Vaejovis spingerus(Wood, 1863), Vaejovidae, Scorpiones, Arachnida. Arthropod Struct. Dev., 31(3): 185- 202.

Yack, J.E. (2004). The structure and function of auditory chordotonal organs in insects. Microsc.Res.Tech., 63(6): 315- 337.

Yang, Q.Z. (1983). The identification of motor neurons innervating an abdominal ventilatory muscle in the locust. J. Exp. Biol., 107: 115 - 127.

Youssef, N.N.(2005 a). Musculature, nervous system and glands of metasomal abdominal segments of the female of Nomia melanderi CkII.(Hymenoptera, Apoidea). $J$. Morphol., 125(2): $205-217$.

Youssef, N.N.(2005 b). Musculature, nervous system and glands of metasomal abdominal segments of the male of Nomia melanderi CkII.(Hymenoptera, Apoidea). J. Morphol., 129(1): 59 - 79. 